\title{
WITHIN THESE WALLS: EXPLORING THE MENTAL HEALTH EXPERIENCES OF FIRST GENERATION SOUTH ASIAN WOMEN IN TORONTO CANADA
}

by

Aneesa Atta, BSW, Ryerson University, 2018

\author{
An MRP \\ presented to Ryerson University \\ in partial fulfillment of the \\ requirements for the degree of \\ Master of Social Work \\ in the program of \\ Social Work
}

Toronto, Ontario, Canada, 2020

(C) Aneesa Atta, 2020 


\begin{abstract}
AUTHOR'S DECLARATION
I hereby declare that I am the sole author of this MRP. This is a true copy of the MRP, including any required final revisions.
\end{abstract}

I authorize Ryerson University to lend this MRP to other institutions or individuals for the purpose of scholarly research

I further authorize Ryerson University to reproduce this MRP by photocopying or by other means, in total or in part, at the request of other institutions or individuals for the purpose of scholarly research.

I understand that my MRP may be made electronically available to the public. 


\begin{abstract}
Within These Walls: Exploring the Mental Health Experiences of First Generation South Asian Women Toronto Canada

Master of Social Work, 2020

Aneesa Atta

Social Work, Ryerson University
\end{abstract}

This research paper explores the mental health experiences of first-generation South Asian women in Toronto, Canada. This research paper starts by providing a brief overview of mental health literature from a South Asian perspective. A qualitative narrative methodology is used to explore what mental health experiences are faced by first-generation South Asian women and their experience of accessing support services in Toronto. Three individual interviews were conducted. Participants were provided with an opportunity to share their experiences of what mental health and recovery mean to them, the mental health stressors they face, the different barriers they encounter when accessing mental health services, and coping strategies employed. This research contributes to a broader understanding of mental health within the South Asian communities and how mental health service providers can work towards a more inclusive and culturally responsive practice when supporting South Asian women. 


\section{ACKNOWLEDGEMENTS}

I want to take this opportunity to acknowledge my MRP supervisor Dr. Gordon Pon, for his support and guidance throughout this research process. Thank you for your flexibility, feedback, and sharing your knowledge of anti-racism and anti-colonialism with me. It was a real honour to work with you.

I would also like to offer my gratitude to my research professor and second reader, Dr. Purnima George. Your knowledge and constructive feedback greatly enhanced not only my paper but my understanding of the importance of AOP research.

I am sincerely grateful to the three women who shared their stories with me and allowed me the honour of presenting their narratives in this paper. Your strength, resourcefulness, and resilience are inspiring.

My heartfelt gratitude goes to my mom for her unvarying love and support, even when we disagree with each other. Thank you for always being there, believing in me, and for encouraging me to do my best.

A special thanks go to my siblings, who went out of their way every single day to remind me that I had a paper that I needed to work on and complete to graduate. 


\section{DEDICATION}

This MRP is dedicated to the most compassionate, hardworking, and dedicated man I know, my

father. My father left his home, family, and all that he knew behind to find a place where his children could have the academic opportunities he was denied. No amount of thanks will ever compare to all the sacrifices that he has made. He has always placed his family and their wellbeing before his happiness and comfort. While the road ahead is filled with uncertainties, I know that the principles of social justice, equity, and patience that you instilled in me will always help guide me. 


\section{TABLE OF CONTENTS}

Abstract

Page \# iii

Chapter 1: Introduction

Page \# 1

Chapter 2: Literature Review

Page \# 5

Chapter 3: Theoretical Orientation

Page \# 14

Chapter 4: Methodology

Page \# 19

Chapter 5: Findings and Analysis

Page \# 28

Definition of Mental Health and Recovery

Mental Health Stressors

Barriers to Mental Health Services

Coping Strategies

Chapter 6: Implications

Page \# 63

Chapter 7: Conclusion

Page \# 71

Appendices

Page \# 73

Reference List

Page \# 84 


\section{LIST OF APPENDICES}

Appendix A - Recruitment Email

Page \# 73

Appendix B - Recruitment Flyer

Page \# 74

Appendix C - Consent Form

Page \# 75

Appendix D - List of Resources

Page \# 79

Appendix E - Interview Questions

Page \# 80

Appendix F - Follow Up Email

Page \# 82

Appendix G - Artwork Consent Form

Page \# 83 


\section{Chapter 1: Introduction}

The purpose of this research is to explore the mental health experiences of firstgeneration South Asian women in Toronto, Canada. The study aims to closely examine how the intersecting identities (race, sexuality, gender identity and expression, religion, and spirituality) of South Asian women impact their mental health and the possible barriers that these individuals might face in accessing mental health services in the city. Furthermore, I would like the research to critically explore some of the strengths, limitations, barriers, and gaps in the current mental health services offered in the city for the South Asian community. I hope that this research will show the importance of engaging with marginalized and racialized communities in the city of Toronto to create more accessible pathways to mental health care that provide culturally informed mental health supports and services.

Canada is one of the most diverse countries in the world, with individuals of South Asian origin constituting the largest racialized group living in Canada (Statistics Canada, 2013). In Canada, the number of individuals that are of South Asian descent, is growing considerably faster than the overall population (Tran, Kaddatz, \& Allard, 2005). As defined by Statistics Canada, Canadians of South Asian origin include several different ethnic or cultural backgrounds, including East Indians, Bengalis, Pakistani, and Sri Lankan (Tran et al., 2005). Furthermore, the majority of the population with South Asian origins living in Canada was born outside the country and resided in Toronto or Vancouver (Tran et al., 2005). Despite the large population, within Canadian society and literature, the experiences of South Asian women continue to remain relatively invisible.

This research is also relevant because, within South Asian communities, the subject of mental health is still widely stigmatized and misunderstood by many. Mental health and mental 
wellness are not discussed. There is a tendency to place blame on the individual if they are faced with a challenge that they cannot cope with. This can create more alienation, marginalization, and disillusionment for someone that is already struggling with mental health concerns. This research can help bring awareness and start a conversation about the impacts of mental health within a community where it is rarely discussed.

The twenty-first century has ushered in a world that has been significantly restructured by neoliberal capitalist globalization (Arat-Koç, 2010). In this period, Canada persistently established an international reputation for being a progressive nation that was welcoming, multicultural, inclusive, and post-racial. This dominant narrative of Canada ignores the complex realities and experiences of inequality, exclusion, and oppression that racialized individuals in the country face within the economic, social, cultural, and political realms (Arat-Koç, 2010). The dominant narrative that Canada is a country that is colour-blind, and everyone has equal access to freedom, opportunity, and the ability to rise to positions of power has been one that is often repeated. This dominant narrative fuelled my interest in conducting research to understand and shed light on the history of oppression faced by first-generation South Asian women in Canada and the impact that it has had on their mental health.

First-generation South Asian women face a unique challenge when addressing their mental health. They can face barriers that impact their mental health on systemic and institution levels, such as racism, othering, silencing, and negative media portrayals. This paper has the potential to contribute to critical transformative anti-oppressive practice as it will examine the overt and covert ways in which colonization, racism, marginalization, and othering of racialized bodies within Canada has impacted the mental health of first-generation South Asian women, their bodies and their access to mental health services and supports. For many first-generation 
South Asian women, colonialism influenced the South Asian diaspora and was a reason that they had to leave their country of origin. Only then to come to a country where they are marginalized can significantly impact their mental health. The study can also offer counter-narratives of Canadian experiences while highlighting the resilience shown by first-generation South Asian women as they address their mental health and navigate their complex identities. While there are a limited number of appropriate services and supports in the city of Toronto to help this population, South Asian women do utilize alternative coping strategies to help them deal with their mental health despite the barriers, intersecting identities and forms of oppression, such as building their own communities. This research can be used as a platform to offer stories of those who are often silenced in mainstream media and discourses.

The structure of this MRP starts with a literature review that highlights an overview of some of the literature on mental health from a South Asian perspective. The research conducted utilizes a qualitative narrative methodology and will focus on exploring how South Asian women understand, experience, and interpret their mental health and their experience of accessing mental health services in the city of Toronto. Three individual interviews with first-generation South Asian women were conducted. The findings and discussion were analyzed through a critical race feminism framework. The key findings were the following: The participants of the study Shreya, Nadia, and Sana all had different definitions of mental health and recovery. The three women shared that intergenerational and cultural conflict, patriarchal gender roles in the household, identity crisis, and addictions and substance use were stressors they felt impacted their mental health. Several barriers to mental health service access were highlighted, including affordability/long wait times, lack of culturally responsive services, and discouragement from within the community and culture. Finally, the women shared coping strategies they employ to 
improve their mental health, such as forming their communities, creating art, and obtaining financial security. The paper will conclude with recommendations made by the research participants on how to improve formal mental health services and the changes that they wish to see from the community. This study aims to provide exploratory information on the real-life daily experiences of these women whose voices are underrepresented in the research on mental health. 


\section{Chapter 2: Literature Review}

Despite a large number of South Asians living in Canada, there is a limited amount of research aimed at the mental health experiences of South Asians in the Canadian context. Moreover, there is even less literature regarding the experiences of young first-generation South Asian women. South Asian immigrant women are from a variety of ethnic, cultural, and linguistic backgrounds. The term South Asian refers to individuals from India, Pakistan, and Sri Lanka, as well as those from Africa, Mauritius, Fiji, the Caribbean, Guyana, Great Britain, and European countries who trace their origins to the Indian subcontinent (George \& Ramkissoon,1998). For the purpose of this paper, I have examined literature that focuses on South Asians and mental health within Canada, the United States, and Britain. Disciplines present in the literature include social work, medicine, psychology, and public health and orthopsychiatry.

\section{Summary of Major Themes:}

Mental health is the overarching theme that links all the literature that I have selected to review. Research participants were shown to have varying definitions of mental health that incorporated psychological, cognitive, social, environmental, and behavioural aspects (Islam, Multani, Hynie, Shakya, \& McKenzie, 2017).

Other major themes that emerged are as follows: mental health stressors, acculturative stress, culture, barriers to mental health service access, and coping strategies.

All of the research studies looked at different mental health stressors that have impacted participants. Academic pressure, family conflict, relationship stress such as marriage, dating, and opposite-gender interactions, financial stress, divorce, climatic and food change, loss of social support, discrimination were all stressors that were mentioned to have negatively impacted 
participant's mental health (Ahmad, Shik, Vanza, Cheung, George, \& Stewart, 2005; ChewGraham, Bashir, Chantler, Burman, \& Batsleer, 2002; Hussain \& Cochrane, 2002; Islam, Multani, Hynie, Shakya, McKenzie, 2017; Samuel, 2009; Tummala-Narra, Deshpande, \& Kaur, 2016; Arora, Metz, \& Carlson, 2016; Inman, 2006; Masood, Okazaki, \& Takeuchi, 2009; Surood \& Lai, 2010).

Acculturation and acculturative stress were mentioned when discussing the mental health experiences and struggles of participants in eight of the research studies (Ahmad et al., \& Stewart, 2005; Hussain \& Cochrane, 2002; Islam et al., 2017; Samuel, 2009; Tummala-Narra et al., 2016; Arora et al., 2016; Inman, 2006; Surood \& Lai, 2010). Acculturation was conceptualized as a multidimensional process that involves participating in heritage culture and/or new culture and developing a sense of biculturalism where immigrant-origin individuals maintain a connection to the heritage culture while adopting values, beliefs, and behaviours of the new culture (Samuel, 2009, p. 17). The stressors accompanying acculturation are known as acculturative stress. Acculturative stress has been associated with psychological distress and mental health symptomologies such as anxiety, depression, substance abuse, self-harm, and suicidal ideation. Acculturative stress is rooted in several challenges, including adjusting to a new and unfamiliar family structure and roles, pressures of learning English, obtaining a job, minority status, and discrimination (Samuel, 2009). Literature shows that South Asian women who have migrated to Canada, are at particular risk of acculturative stress. Characteristics of acculturative stress can include intergenerational conflict, discrimination, and depression (Ahmad et al., 2005).

Participants across eight of the research studies reported both systemic-level and family and community-level barriers to mental health service access (Ahmad et al., 2005; Arora et al., 
2016; Chew-Graham et al., 2002; Hussain \& Cochrane, 2002; Islam et al., 2017; Samuel, 2009; Tummala-Narra et al., 2016; and Surood \& Lai, 2010). At the mental health system level, participants noted the lack of South Asian mental health professionals in the field, lack of representation of people of South Asian background in mental health promotion, long wait times, prohibitive fees for services not covered by the Ontario Health Insurance Plan (OHIP), lack of professionals specialized in youth issues, and lack of variety in terms of models of mental health care (Islam et al., 2017). Some participants felt the excessive focus on treating mental health through medication, and lack of consideration of how religion and other social factors affect mental health made medicalized models of mental health care difficult to accept (Islam et al., 2017; Samuel, 2009). Other concerns regarding medication that were raised were that medication was not a good idea as there were many side effects (Hussain \& Cochrane, 2002; Samuel, 2009; Surood \& Lai, 2010). The cost of medication due to economic hardship and language barriers were also listed as barriers to accessing health services (Ahmad et al., 2005).

The concept of izzat (i.e., 'honour/respect') and the community grapevine (rumour mill) was discussed as a significant influence in South Asian family life and a barrier to accessing mental health services (Chew-Graham et al., 2002). In some families, izzat was given precedence, and preference over the care and happiness of children could be used to reinforce women's roles in family life and was a potential tool to coerce women into remaining silent about their problems (Chew-Graham et al., 2002). The burden of a family's izzat is usually unequally placed upon the women of the family, leading to high expectations of women as daughters, daughters-in-law, sisters, wives, and mothers. The community grapevine resulted in a phenomenal lack of privacy and space for women, and lead to continuous 'gossip' if any women were seen as "behaving inappropriately." Many participants revealed that they felt that if they 
discussed any personal issues or were seen help-seeking, this information would get back to either their own families or others in their community (Chew-Graham et al., 2002).

Culture was also mentioned as a barrier to mental health service access as culture is believed to play a role in the attitudes toward mental illness and mental health services. Participants shared that their cultural values discouraged self-disclosure outside the family, and valued emotional restraint, self-control, and social conformity. These cultural attitudes deterred them from seeking mental health services as a public display of emotional instability may be viewed as a poor reflection on the individual as well as on their family and/or community (Arora et al., 2016).

Coping is a strategy employed by individuals to comprehend, respond, or counter the negative experience (Samuel, 2009). South Asian respondents, in one study, reported that they commonly used emotion-focused coping to deal with acculturative stress. These emotionfocused coping included strategies that involve self-preoccupation, fantasy, or other conscious activities related to affect regulation (Samuel, 2009). In addition, they also handled difficult situations by sharing with family and friends. The majority of respondents in this study did not utilize any professional counselling or therapy of any form as they felt that mainstream counsellors could not understand the problems encountered (Samuel, 2009). Only two participants stated that counselling was a way for them to alleviate stresses and strains within the family. These participants also shared that they believed that counselling sessions would be a good coping strategy for their second-generation daughters (Samuel, 2009).

The literature that focused on coping strategies revealed that many different coping strategies are utilized by South Asian immigrants of different ages, gender, and backgrounds. One study found that the women's major coping strategies included increased efforts to socialize, 
the use of preventative health practices, and self-awareness (Ahmad et al., 2005). Support within immediate and extended South Asian American families was also seen as a possible coping strategy for some (Masood et al., 2009). Among South Asians in the U.S., family cohesion and peer support were found to protect against acculturative stress (Tummala-Narra et al., 2016; Masood et al., 2009). Coping through seeking social supports reflected the collectivistic roots of South Asian cultures. (Masood et al., 2009; Tummala-Narra et al., 2016). Another study found that South Asian women saw self-harm as a usable coping strategy to deal with their distress (Chew-Graham et al., 2002).

\section{Epistemological Paradigms:}

Epistemology, also known as the "the theory of knowledge," is the branch of philosophy that concerns itself with human knowledge and forms the foundation and explanation for what can be considered as knowledge in the western tradition (Williams, 2001). The epistemological framework used by researchers influences every part of knowledge construction. Paradigms are the understandings that ground us in the world that guide and influence our knowing, being, and doing (Absolon, 2011). Together, epistemologies and paradigms influence every part of one's research, including but not limited to the methodology, data analysis, and dissemination of results (Absolon, 2011). Therefore, it influences the questions we ask, how we go about gathering information, how we interpret the results, and what we choose to do with findings.

For this literature review, four quantitative studies were selected (Arora et al., 2016; Inman, 2006; Masood et al., 2009; Surood \& Lai, 2010). In addition, six of the studies used a qualitative methodology (Ahmad et al., 2005; Chew-Graham et al., 2002; Hussain \& Cochrane, 2002; Islam et al., 2017; Samuel, 2009; Tummala-Narra et al., 2016). None of the studies discussed in this literature review utilized mixed methods methodology. 
The quantitative studies that were selected were all guided by a positivist paradigm, although it was not explicitly stated. A positivist paradigm is used to discover natural laws to allow people to predict and control events (Neuman, 2013). The studies operated on the assumption that external forces shape human nature. The studies all looked at how external forces are influencing the mental health of the participants; the research is based on empirical observations and is assumed to be value-free. The studies are all presented in the third person, the researcher is seen as an expert and to ensure that the results are viewed as objective the studies use random sampling (Arora et al., 2016; Inman, 2006; Surood \& Lai, 2010) and surveys (Masood et al., 2009). When applied to the social sciences and looking at the diverse lived realities of individuals and experiences of their mental health, positivism provides a surface-level glance of a complex process that does not adhere to one stable pre-existing pattern.

While the qualitative research studies selected utilized more diverse paradigms and theoretical frameworks, some positivist values were still incorporated. The studies used social determinants of health (SDOH) and an intersectionality lens (Islam et al., 2017), psychological acculturation framework (Ahmad et al., 2005; Samuel, 2009), socio-ecological perspective (Tummala-Narra et al., 2016), and constructivist paradigm (Hussain \& Cochrane, 2002). Furthermore, the studies used focus groups (Ahmad et al., 2005; Chew-Graham et al., 2002) and narrative interviews (Hussain \& Cochrane, 2002; Islam et al., 2017; Samuel, 2009; TummalaNarra et al., 2016). Many of the studies used a third person narrative. Only one study (Hussain \& Cochrane, 2002) explicitly stated that they challenge the notion that research is objective and noted that the researcher's prior knowledge of a topic is not to be ignored or minimized (p. 291). In only one of the studies did the researchers situate themselves when working with participants (Hussain \& Cochrane, 2002). The researchers mentioned that they disclosed their own values, 
ethnicity, and work experience to the participants; however, what was precisely said was not included in the final paper for the reader.

\section{Knowledge Construction:}

It is rare in traditional positivist research to look at who has been involved and who has been excluded from the construction of knowledge. Instead, we are told to assume the researcher is an objective being. When looking at both the quantitative and qualitative studies selected for my literature review, the only indication I had that those who were involved in knowledge production might have some lived experience related to the topic was based on the names of the authors (Ahmad et al., 2005; Hussain \& Cochrane, 2002; Inman, 2006; Islam et al., 2017; Masood et al., 2009; Surood \& Lai, 2010; Tummala-Narra et al., 2016).

The quantitative research and even a few of the qualitative studies took the position that they were conducted to help establish best evidence-based practices. This knowledge is going to be used for training mental health professionals, counsellors, practitioners, social workers, teachers, doctors, researchers, and policymakers (Ahmad et al., 2005; Arora et al., 2016; ChewGraham et al., 2002; Hussain \& Cochrane, 2002; Inman, 2006; Islam et al., 2017; Masood et al., 2009; Surood \& Lai, 2010; Samuel, 2009; Tummala-Narr et al., 2016). The research studies all directly stated that the implications of the research were to make improvements to practices in mental health at the individual and institutional levels. The studies all failed to mention how their research could have possible negative implications on the participants or the communities involved. This concern was raised several times by the participants in one particular study where they stated that word could get out into the community that they were talking about their problems, which could impact their honour (Chew-Graham et al., 2002). 
While the knowledge producers did not identify themselves within the research, those that were researched, across all the studies, were all South Asians living in Canada, the United States, and Britain. They were of all of different ages and genders.

\section{Exclusions:}

After examining the literature available, I noticed that it was difficult to find any recent studies pertaining to young South Asian women. The literature that was looking at South Asian youth's experiences looked at the experiences of all genders and did not account for the differences experienced by women (Islam et al., 2017). The research also missed an opportunity to examine how this population that has been growing up with the internet and rapid technological advancements in a very short period of time has had their mental health impacted. However, one study did briefly mention that the youth have used the internet to become more informed about treatment options regarding mental health (Islam et al., 2017). The literature also did not incorporate the voices of individuals with physical disabilities consumer survivors, or the experiences of anyone identifying as LGBTQ+. The voices that were left out of the literature were the voices of those with many different intersecting identities (e.g., sex, gender, education, race/ethnicity, sexuality, ability, etc.). These intersections play a part in impacting their vulnerability to experiencing mental health challenges but also their experiences and the system's responses to them. Incorporating these voices would allow the research to be more social justice-oriented and give a voice to the most vulnerable communities.

\section{Epistemological Issues:}

I hope to start responding to the epistemological issues in the current research by first identifying myself as a researcher with lived experience. To ensure that the research is antioppressive and social justice-oriented, we must also recognize how we are implicated in 
sustaining systems of inequality, especially in research activities (Potts \& Brown, 2015). In order to do research differently, we must be open to accepting that things outside of our norm also count as knowledge. Part of this involves unlearning values that have been ingrained in us by dominant discourses and teachings such as holding Western knowledge paradigms as superior to others, valuing objectivity over subjectivity, valuing large sample sizes, and looking for one truth (Potts \& Brown, 2015). To truly apply this to my practice, it will be essential for me to practice critical reflexivity throughout the research process and by addressing issues of positionality, identity, and confronting any power dynamics arising between the researcher and the researched (Hunter, 2002).

A common problem with many cross-cultural research studies is that it assumes shared definitions of mental illness (Kleinman, 1987). I intend to have my work be guided by a constructivist/relativist perspective and will acknowledge that there is no singular definition of mental health or mental wellness, and instead, participants will share what their definition is. A constructivist perspective also challenges the notion that research is objective and acknowledges the researcher's prior knowledge of a topic as a reality and not as something that is to be ignored or minimized (Chamberlain, Stevens, \& Lyons, 1997). The research will aim to give a platform for individuals, who have often been stereotyped and silenced, to share an alternative story that too often is ignored. 


\section{Chapter 3: Theoretical Framework}

Critical Race Feminism (CRF) has guided the theoretical framework of this Major Research Paper. CRF was developed as a derivative of critical race theory (CRT) and is "a body of writing that attempts to integrate the way race and gender function together in structuring social inequality" (Dua, 1999, p. 9). CRT focuses on uncovering the institutional constraints that are placed on certain bodies and communities based on their race. CRT also explores critical questions about the notions of equity and diversity along racial lines and hierarchies in hopes of making changes and transforming the detrimental social situations of people of colour (AratKoc, 2010).

\section{Critical Race Theory (CRT):}

Critical Race Theory (CRT) examines issues of power, race, gender, and class, among other social inequalities that are implicated educational institutions (Delgado \& Stefancic, 2012). CRF places emphasis on the legal status and rights of women of color around the world. CRF posed two fundamental questions. The first question was, what is the de jure and de facto legal status of women of color, whether they be minorities within the United States or Europe or part of majority cultures in the developing world? (Pratt-Clarke, 2010). The second question was, what can a focused theoretical framework do to affect their condition beneficially? (Pratt-Clarke, 2010).

CRT can be a useful starting point to understand the mental health experiences of firstgeneration South Asian women in Canada. CRT investigates critical questions about the notions of equity and diversity along racial lines and hierarchies. CRT also strives to expose institutional constraints placed on certain racialized bodies and communities to make transformative changes to improve the disparaging social situations of people of colour (Arat-Koc, 2010). 
CRT is comprised of a few basic tenets. These tenets include the following: (1) the notion that racism is ordinary and not aberrational; (2) the idea of an interest convergence; (3) the social construction of race; (4) the idea of storytelling and counter-storytelling; and (5) the notion that whites have actually been recipients of civil rights legislation (Delgado \& Stefancic, 2012).

While we can examine the mental health experiences of South Asian women in Canada, CRT helps us understand how race and gender both play a role in impacting the mental health of this group. There are three fundamental foundations of Critical Race Theory (Lynn and Parker, 2006). The first foundation is to bring forward subjugated experiences and to create a platform for experiences that are deemed inconsequential and silenced in mainstream society (Lynn and Parker, 2006) - for example, examining discriminatory experiences from the perspective of South Asian women in order to understand their experiences and how it impacted their mental health and to illuminate discriminatory practices that still occur. These stories also provide us with a counter-narrative of people of colour and challenge the negative dominant discourses that are repeated in order to suppress people of colour in Canadian society. For example, in this research paper, I highlight the narratives of South Asian women who have overcome great obstacles, as it provides a counter-narrative to the dominant narratives that women of this race are oppressed.

The second foundation that CRT argues is that the eradication of racial suppression is necessary, and we must recognize that race is a social construct because it is merely the product of social thought and relations (Lynn \& Parker, 2006). We must understand that race is fluid and shaped by political and structural systems and informed by individual lived experiences (Creswell \& Potts, 2017). Certain races become essentialized through a process of social construction that implicates political pressures and media reporting. This can be seen throughout 
history as South Asian women were viewed as exotic and fetishized figures in one era; and later have been subject to xenophobic violence and exclusion that is targeted toward Muslims as the "other" who is incompatible with Western society (Iftikar, \& Museus, 2018). Currently, South Asian women are portrayed in dominant discourses as submissive and oppressed. This narrative is often used in the West to argue that these women require someone to help save them.

The third foundation addresses race and the intersectionality of gender, class, ability, etc. (Parker \& Lynn, 2006). There are intersecting points of power, privilege, and/or oppression within one's identity, which include race. To understand the mental health experiences of South Asian women, we must also look at other aspects of their identity, such as their gender, class, ability, etc. All these identity markers intersect and have an impact on their overall mental health. Critical Race Feminism:

One of the most significant critiques of CRT is that it does not include social class and gender as part of its framework and places a greater emphasis on race. CRT scholars have addressed the intersectionality of race and other social identities within their analysis and stated that one could not think about race, class, sexuality, or gender as independent from one another. In order to understand the mental health experiences of South Asian women in Canada, critical race feminism can be used to obtain a greater understanding of how gender and race together have a significant impact on mental health experiences.

When researching the mental health experiences of South Asian Women in Canada, using CRF can help understand how both race and gender play an important role in shaping one's identity and mental health experiences. CRF aims to provide an anti-essentialist standpoint on the experiences of women of color. Anti-essentialism argues that there is no essential experience or trait that defines a racial group (Delgado \& Stefancic, 2012). For instance, there is no singular 
"South Asian Canadian experience." CRF challenges the notion of global feminism by arguing that race and class both produce differences that are unique to women of color (Few, 2007).

CRF also honours stories and relies on storytelling as a means of constructing and communicating experiences. Storytelling is grounded in the belief that stories of oppressed and exploited people constitute valuable knowledge and can be utilized to counter dominant narratives (Delgado \& Stefancic, 2012). CRF stories and counter-stories are used as powerful means to integrate and dismantle racism (Few, 2007). CRF also uses counternarratives as a point of resistance against narratives that produce the racialization of women of color (Few, 2007). A primary goal of CRF is to construct a counternarrative that highlights the voices of women of color and the impact of the intersections of their identities on their experiences (Few, 2007).

CRF emerged to question the interlocking systems of oppression experienced by women of color (Few, 2007). CRF continues to draw on feminism to distinguish the experiences of women of color from those of men of color. The focus of CRF is to challenge social injustices and eliminate the inequalities experienced by women of color, which makes this framework appropriate for this research. Critical Race Feminism also distinguishes itself from critical race theory by critiquing settler colonialism and Islamophobia while providing a strong analysis of Indigeneity (Razack, Smith, \& Thobani, 2010).

Early critical race feminist theory in the United States framed its interventions around the historical and contemporary experiences of women of colour (Razack, Thobani, \& Smith, 2010, p.21). Within Canada, critical race feminism frames its interventions around the "experiences of Indigenous people within the Canadian settler state and Indigenous women within feminism; the challenges posed by the settler state for women of colour and Indigenous women; and the 
possibilities and limits of an anti-colonial praxis within a settler state" (Razack, Thobani, \& Smith, 2010, p.21).

Critical race feminism addresses settler colonialism and Islamophobia by utilizing a "critical-emancipatory lens to go beyond critical race theory and ask fundamental questions about race and gender and the "colour line" in the twenty-first century; about racialized, gendered relations in an ostensibly race and gender-neutral liberal state; and about the ways in which these interlink with continuing coloniality and the Indigenous dispossession in the settler state" (Razack, Thobani, \& Smith, 2010, p. 21).

CRF acknowledges that race and gender "shape the political economy of life chances, particularly in areas of access to education, employment and income, and housing and that many disciplines fail to account for the ways in which race-making is political and a central project of the modern liberal state" (Razack, Thobani, \& Smith, 2010, p. 21). For South Asian women that have immigrated from the Global South, race does not exist outside of class (and other aspects of social differences), and class does not exist outside of race (and other aspects of social differences). Their intersecting identities are interconnected and impact them psychologically, physically, socially, and spiritually. In using CRF, this research is committed to providing a critical analysis of race and racism in all respects while placing a greater emphasis on women's unique experiences of oppression and resistance. Storytelling will be central in this research to counter dominant narratives and to give voice to the oppressed. 


\section{Chapter 4: Methodology}

This section of the paper will examine the methodology used to design and carry out this research. This study implements a qualitative narrative approach, where participants are able to share their experiences and stories with the researcher. I will use a qualitative approach as it allows me, the researcher, an opportunity to take the participant's story and use it to develop common themes, patterns, and relationships.

\section{Research Goals:}

This research is aimed at examining experiences of first-generation South Asian women related to their mental health in Canada. This study hopes to understand the lived experiences of South Asian immigrant women and their narratives in relation to accessing mental health services and supports in Toronto, Canada. The research question asks, "What mental health experience are faced by first-generation South Asian women, and what are their experiences of accessing support services in Toronto?" Due to the fragmented nature of mental health services in Toronto, this study is interested in learning more about these women's experiences in locating and going about accessing support services. The study is also interested in learning about what challenges these women face while accessing these services and what strengths they utilize in overcoming the barriers they face.

\section{Data Collection:}

The first step in my study involved the review of existing literature that can inform the study and data collection. In order to review the literature for this paper, I used the Ryerson University library to collect articles and books from different databases. Some of the key databases that I used included Social Work Abstracts, Sociological Abstracts, and ProQuest Research Library. Some of the search terms that I have used so far include "South Asian and 
female," "South Asian diaspora," "South Asian and mental health," "discriminations and racism in Canada" and "mental health and immigration." I discovered early into the literature review that it was a continuous challenge to find firsthand data that related directly to my selected topic. However, I was able to locate some research regarding the mental health experiences of South Asians within the US, UK, and Canadian contexts.

The research participants for this project are South Asian-immigrant women who reside in Toronto. At some point in their lives, the women in this research have accessed mental health supports in the city of Toronto. While there are many women in the city who self-identify as South Asian, this study only focused on women who were born in South Asian and emigrated to Canada. All of the women interviewed were immigrants from South Asia and have immigrated from Pakistan and India. The experience of immigration is a unique one that can profoundly impact the trajectory of one's life and mental health. Immigration also has the potential to change how narratives are constructed about an individual and create a distinctive experience where individuals find themselves learning to balance two different cultures. Therefore, this research only recruited those who have emigrated to Canada instead of second or third-generation South Asian women born in Canada. This study also focused on women who use or have used mental health services in Toronto. For this reason, I only recruited women who are currently using mental health services or who have used them in the past. This is because this group of women are in the best position to discuss both the experience of searching for services as well the quality and flexibility of the services that they use or have used in the past.

The three women interviewed for this study were recruited through informal social media groups for South Asian women. While I considered using community agencies and to recruit for this research, informal recruitment methods were selected to find participants. This decision was 
made due to the limited time frame available for the MRP and the fact that formal agencies require time to review and approve project proposals before allowing researchers to recruit from their programs.

After I obtained approval for this study from Ryerson University's Research Ethics Board (REB), South Asian Women's groups located in Toronto, Canada were contacted (See Appendix A - Recruitment Email). The recruitment of participants utilized criterion sampling to locate potential participants through recruitment flyers using social media websites. (See Appendix B Recruitment Flyer). Criterion sampling utilizes a predetermined set of criteria in which participants must meet (Creswell, 2007). Contact was made via email and was initiated by interested participants. Interested participants were provided with both my email address and phone number. Participants were then able to communicate with the researcher through their preferred method.

Upon meeting the inclusion criteria, participants received a consent form (See Appendix $\mathrm{C}$ for Consent form). Inclusion criteria required participants to identify as first-generation immigrants and women from South Asia living within Toronto, Canada. Participants must identify as first-generation immigrants as the research is looking at the unique perspective of those that moved to Canada from South Asian. Participants must also self-identify as women since the research is looking at the experiences of those who identify as women. Participants must be able to speak and understand English (either as a first or additional language). The rationale for this criterion is that it was the language that the researcher was most proficient and fluent in.

Six potential participants approached the researcher to participate in the study. However, due to the nature of the project's size and time limitations, a maximum of three participants were 
recruited. The first three participants who met the inclusion criteria were selected. Given the sample size of three participants, I make no claims of the representativeness of the sample size or generalizability of the findings. A narrative approach does not require a large sample size and is best suited for gathering in-depth, comprehensive stories (Creswell, 2007). Small sample sizes are not uncommon in qualitative studies, and this research aims to try its best to bring forth stories being shared with me.

Three South Asian women who currently reside in Toronto, Canada, were recruited. All participants were born in South Asia (Pakistan and India) and immigrated to Canada with their families. Participants' ages ranged from the mid-twenties to early thirties. All participants came to Canada as landed immigrants. Two of the three participants interviewed were in relationships, while one is a single. One participant was also a single parent. All three of the women in the study spoke English and have obtained undergraduate degrees from Canadian universities. All three of the participants in the interviews communicated that they have dreams of pursuing their education further; however, at this time they are unsure when they will be able to do so. It was observed that all three women currently reside with their families, although all mentioned that they wish to move out and live on their own.

\section{Approach:}

This study implements a qualitative narrative approach, where participants are able to share their experiences and stories with the researcher. A qualitative approach was utilized as it

allows the researcher an opportunity to take the participant's story and use it to develop common themes, patterns, and relationships. A narrative approach collects an individual story about their experiences and lives (Creswell \& Poth, 2017). A narrative approach to qualitative research allows the participants to tell the researcher "narrative stories of their individual experiences and 
they may shed light on the identities of individuals and how they see themselves" (Creswell \& Poth, 2017, p. 69). Narrative methodology will also allow the researcher to ask participants to speak and share their stories regarding how their self-identities have shaped their journey and mental health experiences. Narrative interviews should be viewed as a conversation, a partnership between the researcher and research participants, and the researcher must recognize that they play a key role in constructing the data presented, which is the participants' stories (Riessman, 2008).

The study involved conducting three one on one qualitative semi-structured telephone interviews with first-generation South Asian women residing in Toronto, Canada. A narrative approach was utilized to capture and represent the experiences of first-generation South Asian women in Toronto. A narrative approach helped the researcher best examine the lived experiences of these individuals. Due to the unprecedented events of COVID-19, all the interviews took place by phone or through an online video call in order to adhere to social distancing protocols and to maintain the safety and confidentiality of all the participants. All signed consent forms, audio-recorded interviews, interview transcriptions, and contact information collected were placed in a safe space that is only accessible to the researcher. Participant's email and phone number were also collected for the sole purpose of facilitating interview arrangements and correspondence with participants during the research process.

All information was kept confidential, and when reporting the findings of the study, all identifying information was removed from transcripts, and pseudonyms will be used in place of the participant's names to ensure confidentiality. No personal information that can identify a participant was included in the final research paper. All data was kept confidential and securely stored electronically with password protection, encrypted USB, and deleted once the data had 
been coded and analyzed. All data was destroyed after the final paper has been submitted to Ryerson University.

Participants received access to their interview transcripts to review, edit and approve the draft research paper in order to ensure that they are comfortable with the information presented and to confirm that information included does not identify them to potential readers. Participants were advised that participation in this study will be entirely voluntary. The most significant ethical risk for participants of the research was that of identification. To minimize the risk of identification, participants were made aware of the risk and advised not to share very specific details which they felt others could recognize and connect to them. The other potential risk of participation in the study was psychological duress resulting from recounting potentially stressful or unpleasant memories and experiences. To minimize this risk, it was made clear to participants that they could choose whether to be in this study or not. Participants were informed that they could choose to take a break, stop participating in the study, and skip any questions. Participants will be informed that their choice of whether or not to participate would not influence any future relations with Ryerson University or the principal investigator (Aneesa Atta) involved in the research.

After examining the findings of my research, I developed a list of recommendations made by the participants of this study for mental health service providers in the community. This study can also be used to identify critical gaps in the research involving South Asian-Canadian communities.

\section{Data Collection:}

The data collection included recording the audio of the narrative-focused interviews. Over the course of the research, field notes and interviews were also collected. Field notes were 
collected in the form of handwritten notes during and after the interviews. A total of three telephone interviews were audio-recorded using a speakerphone and digital recorder. The audiorecordings allow for accurate transcription of the interviews. All identifiable data, such as names of the participants, were removed from the transcripts. The interviews were around 60 to 90 minutes in duration. In order to minimize risks, participants were encouraged only to share information that they are comfortably able to disclose. Participants were also reminded that they could skip questions, stop the interview, take a break, or withdraw at any point during the interview process. After the interview process, the researcher debriefed with the participants. The participants were also sent an email with a list of community resources that the participant can connect with if support is required (See Appendix D - List of Resources). Participants were also informed that they could contact the researcher at any time for additional information regarding accessing supports and services.

\section{The Researcher: Self Reflection}

Narrative approach honours stories and relies on storytelling as a means of constructing and communicating experiences. "Storytelling is such an important activity because narratives help people organize their experiences into meaningful episodes that call upon cultural modes of reasoning and representation" (Fraser, 2004, p.180). In selecting a narrative methodology, I was conscious of how my own story could impact this research and participants.

Absolon and Willet (2005) state that socially locating at the onset of the writing process is a way to resist colonial writing processes. Socially locating is done during introductions by sharing how one fits into the community (Lavallee, 2009). Through an Indigenous perspective, socially locating is seen as a way of creating accountability and building trust (Absolon \& Willet, 2005). With these suggestions in mind, I would like to introduce myself. 
My social location and lived experiences have afforded me both oppressions and privileges that fueled my values, practice, and research. Firstly, as a first-generation immigrant from a territory that still feels the impact of colonial rule, colonialism and colonial thought have influenced my embodied knowledge. Through living in and knowing about the unpleasant reality of life in Pakistan's occupied Kashmir with paramilitary troops, economic deprivation, lack of education and employment opportunities, and only having the status of conditional citizenship as a direct result of colonialism, I found myself embedded in an identity that opposes the dominant colonial paradigms. As a first-generation immigrant who moved to Canada as a young child and first-born girl in my family, I faced challenges and learning curves that were different in comparison to others around me. I had to learn how to navigate between two different cultures, each with their own rules and expectations of what was acceptable. In addition, I had to learn through trial and error how to navigate colonial institutions in Canada, such as the educational system, to figure out how to best succeed in a space dominated by colonial thought. I found that the experiences that I had due to my social location and identity impacted my mental health in a way that was similar to those who had comparable experiences as me but different from my peers and even siblings born in this country. This understanding intrigued me to research the experiences of first-generation women of South Asian descent.

My experiences and the impact that it had on my mental health often made me feel as if there was something wrong with me personally. I questioned if anyone else understood what I was going through. It was not until I openly spoke about my experiences that I started to hear about others going through the same experiences. This made me understand the power in telling our personal narratives and giving marginalized voices a place to speak their truth. Therefore, I choose to engage in qualitative research that allows us the opportunity to take an in-depth look at 
the "why" of social phenomena and relies on the direct experiences of people as meaning-making agents in their everyday lives (Glesne, 2016). As the topic is also closely related to my own identity and lived experience, I would not be able to be an objective and neutral researcher and must learn how to use my experience in my research (Baksh, 2016).

A big part of my professional experience in the mental health field comes from working at the Toronto Distress Centre for over two years. I started with the agency as a BSW student completing my fourth-year practicum and continued as a staff member. Through this role, I spent a lot of time speaking one on one with individuals and hearing their life experiences and narratives. I noticed that everyone had a different story to tell, all the stories highlighted different oppressions and resiliency. This experience allowed me to see that everyone had their narrative, truth, and experienced things differently. While something might be oppressive to one individual, that same thing could be seen as empowering for another. This understanding impacted my personal epistemology as I came to learn that everyone should have the right to make their own decision on what is right for them.

In my research, I want to ensure that my personal beliefs are not perpetuating oppression against any group or my research participants. Throughout my research, I ensured that I did my best to be critically self-reflective on an on-going basis to ensure that my personal biases are checked and not unconsciously oppressive toward my research participants. 


\section{Chapter 5: Findings and Analysis}

The three women interviewed for this study have all used mental health services in Toronto at some point in their lives. The major themes that emerged are as follows: definition of mental health and recovery, mental health stressors, barriers to accessing mental health services, and coping strategies. While themes of struggles emerged in the study, positive trends that highlighted the participants' resilience were also observed through the interviews. There are numerous factors that impact an individual's mental health. For racialized women who have immigrated to Canada, their situation becomes more complicated as there are additional barriers that they face due to the intersecting identities they hold. The women interviewed for this study found different ways to cope with and address their mental health despite difficulties being heard, accessing supports/services, and finding a safe space.

In this section, I will first share the personal narratives of the three women that were interviewed for this study. These personal narratives all use pseudonyms that the participants selected for themselves after the interviews were completed. The narratives are presented to allow readers the opportunity to get a glimpse of different aspects of the participants' lives as it relates to the topics discussed. Through the process of member checking, these personal narratives were co-created and approved by the participants based on the information that they provided during the interviews. The narratives describe aspects of the participants' lives, such as their family, educational background, struggles, and the services that they have used. This section will then go on to present the main findings of this research. Interviews, field notes, and personal narratives were used to draw out major themes from the participants' experiences. Four major themes will be examined, and multiple subthemes will be presented that emerged from the data on the participants' experiences. Lastly, I will highlight recommendations made by 
participants pertaining to what mental health services and their own community can do to improve their mental health.

Below is a brief profile of each participant. The names listed below are pseudonyms.

\section{Participant 1 (Shreya):}

Shreya is twenty-four years old and was born in India. When she was a few months old, Shreya and her mom moved to Kuwait, where her father was working at the time. Shreya and her family eventually immigrated to Toronto, Canada, when she nine years old through family sponsorship. Shreya's father wished to move their family to Canada because he wanted to provide his children with a better education. Shreya's parents both hold graduate degrees from university, and once they arrived in Canada, they struggled at first to find a job within their respective fields. Both of Shreya's parents worked entry-level customer service jobs for a few years until they were able to find stable employment in their fields. Shreya went on to obtain a B.Sc. and recently completed a postgraduate certificate in Mental Health and Addictions. Shreya now lives with her parents and younger brother in Toronto, Ontario. Shreya described a day in her life as being expected to help cook, clean, and spend time with her parents. Shreya is currently looking for jobs related to her field of study. She stated that her parents are anxious for her to find a job as soon as possible. The reason they would like her to start working is so that they can start looking for a suitable marriage partner for her. Shreya shared that while her family is Hindu, religion is not a big part of her life. She does enjoy going to the temple occasionally because of the culture, and it gives her the opportunity to meditate. Shreya disclosed that she accessed a therapist through her school at a time where she was experiencing extreme anxiety, panic attacks, and felt isolated. Shreya stated that as a woman from a South Asian background, she noticed at an early age that there were different standards and expectations that her family had for her compared to her brother. She was expected to adhere to a different set of rules that then governed her every decision. This negatively impacted her mental 
health. Shreya has stated that mental health is not discussed in her family. In addition, while there are individuals in her family that struggle with mental health and addictions, no one acknowledges the impact that mental health can have on fueling and sustaining addictions. For formal mental health services, Shreya has turned to her family doctor, a counsellor she contacted in Toronto, and a distress line. One of the main strategies that Shreya uses to cope with her mental health is through art.

\section{Participant 2 (Nadia):}

Nadia is twenty-five years old and was born in Pakistan. Nadia and her family immigrated to Canada when she was in grade one. Nadia's family is comprised of her mom, dad, two older sisters, and one younger brother. Shortly after her family moved to Canada, Nadia's father returned to Pakistan so he could continue working and supporting the family. Nadia's father moved back to Canada six years later and opened a store. Nadia currently lives with her parents, sister, and brother in Toronto, Ontario. Nadia obtained her undergraduate degree in Human Resources from York University and is currently employed full time at a bank. Nadia described a day in her life as going to work during the day, spending time with her partner or friends, and doing her best to help around the house when possible. In her spare time, she enjoys exercising or spending time with her friends. Nadia describes her family as conservative Muslims. Nadia herself is an ex-Muslim who left the faith three years ago. Nadia wore the hijab from grade eight until she was in her fourth year of university. Nadia revealed she made the decision to remove the hijab after she stopped believing in Islam; however, this decision had a lot of consequences that have negatively impacted her mental health to this day. After removing the hijab, she felt that she was interrogated by her family as to why she made that decision, which led her to confess to them that she does not believe in Islam. Her family pressured her to talk with religious leaders to reconsider her decision and threatened to disown her if she did not reembrace the faith. Nadia's parents also discovered that she was using cannabis recreationally, and an agreement was reached that she could only continue living at home if she 
agreed to stop using any substances and was willing to take a monthly drug test. As Nadia could not afford to move out on her own as a student and to move out meant that her parents would also cut her out of their lives, she consented to the agreement. Nadia stated that she struggles with anxiety, addiction, and has periods where she experiences depression. Nadia relies on her friends and partner to be her support system and uses her art as an outlet to cope with her mental health struggles. For formal mental health services, Nadia has turned to her family doctor and two counsellors from different agencies in Toronto. Nadia has stated that while her relationship with her parents has improved considerably over the years, there is still a lot of work to be done. Nadia shared that mental health has never been discussed or acknowledged in her household and community, and she hopes to see that change.

\section{Participant 3 (Sana):}

Sana is thirty-one years old and was born in Pakistan. Sana immigrated to Québec, Canada, at the age of thirteen with her family and resided there for several years prior to moving to Ontario. Sana completed high school in Montreal and moved to Toronto shortly afterward. Sana stated that her family never actively encouraged her to pursue post-secondary education, and going into the workforce after completing high school allowed her some independence. Therefore, she decided to start working full time in an entry-level position at an office doing administrative work. At the age of eighteen, Sana's family went on vacation to Pakistan for a month. Once in Pakistan, Sana stated that her parents started to pressure her into getting married. Sana stated that her parents continued to extend their vacation in Pakistan until she agreed to get married. As a result, she was forced to resign from work and remained in Pakistan with her family for a year. During that time, she was married to a man that her parents selected. Over the next few years, Sana returned to Toronto to work and occasionally travelled to Pakistan to spend time with her husband until she was able to sponsor him to Canada. Sana's husband arrived in Canada when their son was two months old in 2012. Sana and 
her husband lived together for two months, but regrettably, their relationship quickly became strained. Her husband decided to move out, and they remained separated until their divorce was finalized in 2017. Sana assumed the sole responsibility of raising her son as a single parent, and her husband has had no contact with their son since moving out. Sana went back into the workforce after separating from her husband; however, she realized that her work opportunities were limited without a post-secondary education. Sana then returned to school and is now completing the final year of her undergraduate degree from the University of Guelph-Humber. Sana stated that her daily duties include looking after her son, helping her parents, completing her schoolwork, helping with household chores, and working part-time. Sana stated that her mental health struggles intensified after getting married, leading her to experience anxiety, depression, and suicidal ideation. For formal mental health services, Sana stated that she turned to her family doctor, psychologist, and a counsellor for support. Sana stated that the state of her mental health was not something she could ever share with her family as they would not understand what she was experiencing or why. Sana revealed that she had worked hard to improve her mental health and employs a number of coping strategies, including having a support system comprised of friends, cousins, and her current partner. Sana currently lives with her parents, two brothers, and son in Toronto, Ontario. She hopes to share her story to allow others to know that they are not alone and to encourage dialogue around mental health in the South Asian community.

\section{Themes:}

The following paragraphs discuss the findings of the research. Four major themes and additional subthemes emerged from the data on the participants' experiences of mental health. The first theme is related to the definition of mental health and recovery. The second major theme is mental health stressors. The third major theme is the barriers to accessing mental health 
services. The final major theme is coping strategies, which looks at actions that participants took to mitigate adverse mental health impacts.

\section{Theme 1: Definition of Mental Health and Recovery}

My findings are based on three interviews that took place in June of 2020. I was able to gather data from the interviews that spoke to what the participants considered to be their definition of mental health and recovery. All the participants who were interviewed for the research had different definitions of mental health and recovery. These definitions all contained biological, psychological, social, spiritual, environmental, and behavioral aspects of mental health. Positive mental health was often described as having balance in one's life.

Shreya explained that to her, "mental health means like your overall wellbeing. It can include how you are doing biologically, psychologically, socially. So, it could be bad or good, and to have good mental health, it's like just having that balance."

Nadia shared, "My definition of mental health is how we psychologically cope within a stressful situation and how these stressors affect our overall wellbeing in order to make decisions and behave in a way which is self-conducive to our perception of ourselves."

Sana stated,

"to put it in the most simple terms, to me mental health is our psychological and emotional wellbeing. It's something that we have to actively take care of to make sure we are well. Just like how we take care of our physical health by taking care of any injury that arises, we need to do the same for our mental health by evaluating it. And making sure that the stressful events we face don't cause any injury to our minds and psychological wellbeing".

When speaking about mental health, the participants shared that for them, mental health encompassed both positive and negative elements; however, the key was to have an overall balance between the two states. Shreya and Nadia went into detail to share that their definition of mental health would differ drastically from their family's definition, which focused solely on the 
adverse effects of mental health and associated it with illness. Sana shared that mental health is not acknowledged in her family at all, so she cannot be sure as to how her family would define mental health. However, she believes that if they were asked, they would confuse mental health for mental illness. When asked to discuss their definition of recovery, the three participants talked about how they felt about mental health in relation to wellness. Each of the participants also notably had different definitions of recovery.

Shreya defined recovery as,

"To me recovery is having good mental health overall and having the ability to cope and handle stress and challenges in a healthy way. Also, having a balanced lifestyle and like positive outlook in life. Like when you're faced with triggers, not having it control your emotions and actions but being able to manage them."

For Shreya, having balance was also a key component of her definition of recovery, similarly to her definition of mental health.

Nadia stated,

"I think recovery is being able to create coping mechanisms personalized for yourself, so being able to function within a satisfactory level without self-destruction but focussing on self-preservation, recognizing discrepancies of self-perception and reality.

Understanding where negative perceptions of ourselves come from either throughout childhood or adulthood. Also, understanding that you can't control everything and what you can focus on is your day to day actions, which overall help create progress in the long term."

Sana explained,

"I feel that recovery is being stable again and at peace with your psychological, emotional, and physical health over a long period, although you can occasionally slip. It's about having ways to manage those slips and cope in a manner that does not cause harm to you when you are going through something.

Nadia and Sana both felt that recovery was not a linear process. Instead, they stated that it is an on-going process where one can experience setbacks and challenges. Sana also went on to explain that she felt that recovery is something that one needs to actively work towards by taking 
the time to check in with yourself to see how you are doing. All the participants also mentioned that a strong support network is necessary for recovery and being socially isolated can hinder the process. The participants stated that one of the challenges in working towards recovery was not being able to include their family members in their support network due to the stigma and silencing of any discussion regarding mental health.

Shreya shared,

"I've had family members that struggle with mental health. I also struggle with my own mental health; however, despite all of us struggling, it's still not something that we discuss. If anyone starts to talk about mental health, the conversation will not be taken seriously. If in the odd chance that someone does take it seriously, we're often told that you have to fix what's wrong with you because this is your issue, and you should deal with it. Or you are asked, 'why are you struggling? You have food and shelter, which is all you need. You don't even know what a real struggle is."

Participants shared that for some of their peers, their families have taken an active role in helping them address their mental health concerns; however, for Shreya, Nadia, and Sana, they all stated that they could not turn to their family for support. The participants all revealed that for them, their family plays a significant role in their lives, especially as they live with their family. However, they cannot discuss their mental health with their family for several reasons. Their concerns regarding their mental health are not taken seriously, or if the participants can discuss their mental health, they are blamed for any concerns that they are facing. However, Shreya did mention that within the past year, she has noticed some small changes in her family's attitude towards mental health. As she has spent the last two years studying Mental Health and Addictions in school, she slowly started a dialogue with her parents regarding mental health. 
Nadia stated,

"If I tell my family that I have any problems like I have anxiety, or I'm not feeling well, I'm feeling a little depressed, the first thing out of their mouths usually is well this wouldn't have happened if you prayed or if you were a Muslim or if you went to the mosque. What you're facing is really because you've turned away from Islam, how could you possibly have any peace”.

While religion and spirituality can be a source of support and healing for some, this was not the case for Nadia. Practices, rituals, and beliefs were forced on her without any consideration of her views and preferences. Nadia shared that this made her feel as though she lacked agency, helpless and silenced, and continually having these feelings negatively impacted her mental health.

Mental health is the level of psychological well-being or an absence of mental illness. Lack of well-being is often characterized by emotional distress, low self-esteem, a sense of hopelessness, chronic stress, and anxiety (Bonnie \& Pon, 2015, p. 106). While not everyone has a mental illness, everyone has mental health. Most discussions examine well-being in individualistic terms while not recognizing the implications of broader social, political factors (Bonnie \& Pon, 2015, 106). Structural determinants of mental health such as racism and colonialism may lead to or exacerbate adverse mental health. The notion of well-being is difficult to assess and diagnose clinically; however, the presence of decreased well-being can cause increased substance use, family breakdown, and overall diminished quality of life (Bonnie \& Pon, 2015, p.106). Interlocking oppressions of racism, classism, and sexism filter through dominant Canadian institutions relating to health, social services, education, law, immigration, employment, and housing, and this can exacerbate the adverse mental health of racialized bodies (Bonnie \& Pon, 2015, p.107). In Canada, white supremacy is rooted in the notion that white individuals are proper citizens of the country while socially constructing the idea that Indigenous 
and racialized individuals are threats to the nation. Today, there are still very few people still are willing to acknowledge that Canada is a settler society (Pon, Giwa, \& Razack, 2016). Racism and colonialism manifest today in many ways, such as the government not recognizing Indigenous sovereignty, racial profiling, the over-representation of certain racial groups in prison, and the child welfare state (Baskin, 2009). Research indicates that there is a link between colonialism and health inequities among Indigenous peoples. Well-being, therefore, cannot be separated from poverty, racism, and sexism experienced by racialized people in North America (Bonnie \& Pon, 2015, p.107). Racism can also have a harmful impact on health, contributing to depression, addictions, hypertension, and post-traumatic stress disorder (Bonnie \& Pon, 2015, p. 107). Mental health practitioners are also socialized to be silent around issues of racism despite racism pervading the mental health professions (Bonnie \& Pon, 2015, p.107).

Within South Asian communities' attitudes and behaviours around mental health may vary across different communities and geographies; however, overall, it is still seen as a mostly taboo topic. Because it is a taboo topic, mental health concerns are often kept private and not openly discussed. The lack of discussion and secrecy around mental health prevents individuals from receiving critical education regarding what mental health is and what are the signs, symptoms, and impacts of adverse mental health. As a result, the causes of mental health concerns are also often misunderstood, which in turn contributes to misconstructions and misconceptions regarding what mental health is. This was evident in the findings of this study, as the participants all had differing definitions of mental health and recovery that they created rather than learning from their communities and families.

Many members from South Asian communities, especially those who are older, do not view mental health as physical health, which can benefit from being treated with the assistance 
of professionals (Islam et al., 2017). Instead, there are often misunderstandings about the causes of mental health problems, which include black magic, the will of God, lousy parenting, individual choice, or genetics (Islam et al., 2017). All the participants stated that they did not know the exact word for mental health in their native language. Rather within their communities, mental health problems were synonymous with being "stupid." When sharing the general attitudes and knowledge about mental health that they encounter, participants shared that in their communities the most commonly used the word to describe people with mental health concerns was the Urdu and Hindi word "pagal" which can mean paranoid, irrational, mad, demented, lunatic or deranged given the context. The lack of understanding of mental health and the factors that contribute to it perpetuate both oppression and stigma against those who experience adverse mental health. These findings correlate to those found in the literature review, which highlighted that research participants had varying definitions of mental health that incorporated psychological, cognitive, social, environmental, and behavioural aspects of mental health (Islam et al., 2017).

The varying definitions of mental health and recovery was a prevalent theme throughout all three interviews. Despite the participants' different positionalities, there were many similarities in how the participants viewed mental health and how they believe their communities' perceived mental health. When discussing their communities' perception and definition of mental health, stigma, secrecy, and lack of education were noted multiple times. This suggests that there could be an essence of a universal experience of how South Asian families, communities, and individuals experience mental health concerns that are situated and grounded in a South Asian cultural worldview. This finding corresponds with the current literature regarding South Asian mental health that found that there needs to be an inclusion of 
culture in the basis of epistemology in the field of mental health rather than accepting that the current knowledge and practices are enough when supporting racialized populations (Arora et al., 2016). The cultural beliefs, which include stigma and secrecy concerning mental health in South Asian communities, have the potential to inform current practice and services that are offered in Toronto. The majority of the current practice and services that are available are still privileging Western notions of mental health and are based primarily on mainstream/white approaches. These Western approaches do not equally benefit or provide the support that is required from the growing number of South Asian women that need access to these services. CRT scholars have addressed the intersectionality of race and other social identities within their analysis and stated that one could not think about race, class, sexuality, or gender as independent from one another. To understand the mental health experiences of South Asian women, we must look at different aspects of their identity, such as their race, gender, class, ability, etc. as these identity markers are intersecting points that impact the power, privilege, and/or oppression one has. Western notions of mental health fail to notice the intersections of race and gender and, therefore, cannot adequately support Indigenous and racialized women. Race, gender, and class produce differences that are unique to women of color and have an impact on their overall mental health. (Few, 2007). The Western approach also ignores the complex historical and contemporary realities and experiences of inequality, exclusion, and oppression that Indigenous and racialized individuals in the country face within the economic, social, cultural, and political realms (AratKoç, 2010).

In Canada, settler colonialism has been used to create color lines to produce an image of who the dominant desirable Canadian citizen is and what worldviews were acknowledged. Historically, settler colonialism and white supremacy were normalized to assimilate able- 
bodied European immigrants into North America and excluding and racializing those settlers who were poor, disabled, and female (Lee \& Ferrer, 2014). European settlers established the norm in North American society to be patriarchal, white, middle-class, nuclear family, and heterosexual/cissexual (Lee \& Ferrer, 2014). Capitalism, patriarchy, and ability all worked in intersecting ways to integrate able-bodied people who fit the established norm into dominant whiteness (Lee \& Ferrer, 2014). In turn, this led to the exclusion, racialization, and marginalization of those settlers who were poor, disabled, and female (Lee \& Ferrer, 2014). This process set clear criteria of who could be assimilated and reformed and brought into the circle of reform and those who were viewed as inferior and outside the boundaries (Lee \& Ferrer, 2014). The normalization of settler colonialism and white supremacy also established Western knowledge and approaches as dominant and, as a result, erased and discredited nonWestern ways of knowing and replacing it with a European worldview. To change research and social service practices to support racialized communities, practitioners must be open to accepting that things outside of the Western approach also count as knowledge. Part of this involves unlearning values that have been ingrained in us by dominant discourses and teachings such as holding Western knowledge paradigms as superior to others, valuing objectivity over subjectivity, valuing large sample sizes, and looking for one truth (Potts \& Brown, 2015).

\section{Theme 2: Mental Health Stressors}

Shreya, Nadia, and Sana all revealed that they face many mental health stressors on a daily basis, which in turn adversely impacts their mental health. All the participants noted an array of different mental health stressors that impacted them, such as relationship stress, financial 
stress, career stress, academic pressure, and more. Due to this study's time constraints, the following paragraphs will examine only the key stressors noted by all three of the participants, including intergenerational and cultural conflict, identity crisis, addictions and substance use, and patriarchal gender roles in the household. It was necessary to examine some of the stressors faced by participants as the women revealed that these stressors all contributed to some of the mental health challenges that they faced, such as anxiety, depression, drug use and sleep problems, pain, and bodily complaints such as muscle tension.

\section{$\underline{\text { Intergenerational and Cultural Conflict }}$}

All the participants stated that the intergenerational and cultural conflicts that arises between them and their parents were a mental health stressor for them. The underlying roots of these conflicts arose primarily from the impact of migration and resettlement, which resulted in a dynamic where two different cultures had to learn to coexist under the same roof.

Shreya explained that while her parents came to Canada to allow them to have better opportunities and receive a good education, they had a difficult time adapting to the culture. She stated,
"For as long as I can remember, I've been torn between two different cultures, learning how to balance them and trying to figure out how to keep everyone happy. For example, at school, when I wore clothes that were Indian, I was made fun of. And then at home, if I wore a $t$-shirt or any western clothes, I would be told that was not acceptable. I would be shamed for wearing western clothes that showed an unnecessary amount of skin. The things that were considered normal at school were shamed at home, and the things that were acceptable at home were looked down upon at school. I had to follow the rules that my parents set out for me, and these rules would often be different than anything my friends and classmates were forced to follow."

As a result of being stuck between two different cultures and having a different set of rules in place due to her gender, Shreya often felt lonely and isolated. Shreya noted that her brother could 
not understand what she was experiencing as he was raised by a different set of gendered standards that allowed him more freedoms and agency.

Social constructionism is the principle that there is no biological basis for racial categories, and race is a socially constructed phenomenon (Delgado \& Stefancic, 2012). We can use the work of Edward Said to understand how race is a socially constructed phenomenon. In 1978, Edward Said termed Orientalism to describe the study of Eastern societies and cultures, usually by Westerners. Said (1978) argued that Western societies have sought to dominate the Eastern world. Through the construction of negative generalizations of 'exotic,' Asians Western societies were able to patronize and dehumanize societies and peoples of Asia (Said, 1978). In the early years of contact between the peoples of the East and the West, Western explorers depicted people of Asia as untrustworthy and strange others (Said, 1978). The West was seen as the norm and set the standard around which the rest of the world orbits and, in contrast, the East was established to be the exotic, the foreign, and the other (Said, 1978). These racist constructions still exist and continue to influence the conceptions of these regions today; however, they have taken on a new covert form, which is normalized and seen as acceptable. In Canada, colonialism and white supremacy have promoted the exaltation of all Western elements such as clothing, language, and knowledge while othering anything that was non-Western. In Shreya's case, settler colonialism's operation can be seen through how her peers in elementary school made fun of her Indian clothes because they were non-Western. Her peers made fun of her for deviating from what they were taught was normal and acceptable and unknowingly reinforced the exaltation of all things Western, othered her, and adversely impacted her mental health by making her feel lonely and isolated. 
Nadia and Sana's experiences echoed that of Shreya's. All participants shared that they struggled with balancing two different cultures. The participants stated that it was easier for them to balance between the two different cultures at school than at home. They all believed they had a lot more freedom to choose who they wanted to be at school. However, at home, they did not have the ability to decide which parts of themselves they wanted to express due to rigid cultural expectations that were imposed on them.

Nadia stated,

"In school, especially university, it was a lot easier for me to be who I wanted to be. I could openly say what I felt or talk about my beliefs. Yes, there were people that treated me differently because of my race and background, but it was always in a covert manner, so it did not bother me as much. At home, it was different, especially due to the power dynamic between me and my parents. In my eyes, they had more authority over me, and so I had to follow their rules. If I didn't, they had the power to threaten to kick me out of the house. As a student only working a part-time job in Toronto, I absolutely couldn't afford to move out. So rather than fight with my parents or make them try to adapt, I would give in to what they wanted. They wanted to follow the customs that they grew up with rather than accepting anything from Western culture. So to appease my parents and also make sure I wasn't always suffering, I put up a front where I did and acted how they wanted me to at home and as soon as I was out of the house, I would do as I wanted. I would change into a different set of clothes, I talked to who I wanted and did what I wanted while letting them think that my actions and behaviors in public were the same as they were at home"

Sana further added that for her family, her parents had the final say in everything, and complete obedience was expected. She stated,

"my parents grew up in a culture where you had to respect your parents and do exactly as they said. When I was young and I tried to have any independence, my parents would state that things in our culture were done a certain way and that they always obeyed their parents no matter what, and I was trying to be western and like white people. So rather than fight with my parents or make them try to change, I eventually just gave in to what they wanted. I was tired of constantly fighting with them and living in an environment where tension was always in the air. This has changed considerably since I became a single mom. Now I have more freedom to do as I want. That being said, because my parents are old now, I try to do things that won't upset them too much. They won't be around forever, and I don't want to destroy their mental health at their age". 
Sana explained that when she was younger and tried to deviate from cultural roles and expectations, it would cause many fights, tension, and feelings of resentment in her family, which led to her mental health deteriorating. However, unlike Nadia who formed a separate identity for when she was outside in society, Sana felt the best decision for her was to adhere to the social norms and expectations that her parents set for her based on their culture.

\section{Patriarchal Gender Roles in the Household}

All three of the women interviewed for this study were living with their parents. In addition, of the three participants, Sana was a single mother raising her son while living with her parents. From the interviews with the participants, it was clear that there was a strong patriarchal gender dynamic in the women's households.

Shreya explained that despite being close in age with her younger brother, there were patriarchal gender dynamics that impacted what was expected of her and what she was able to do. She stated,

"The freedom that I have versus what my brother has is very different from what I would have liked. He sometimes just leaves the house without letting anyone know and just comes back hours later, late into the night. For me, I would have to like ask permission. And then I would have to tell them who I'm going with, where am I going, when will I be back and then when I come back, it's like a full interrogation on what happened, down to the little details. And my brother doesn't have like that same experience. I can't do the small normal things that he does every day like leaving the house without feeling anxiety about all the questions I will be asked before going out and after when I come home. It also makes me constantly feel guilty even though I'm not doing anything wrong. So, it's like that's one huge difference in our daily life. This impacted me as it's kept me from doing a lot of things that I would have wanted do, it's also impacted my social development, and I struggle a lot just to feel comfortable in everyday situations." 
Nadia and Sana explained that for them, there was an expectation that they also take part and help with the household chores, in addition to contributing to the family financially. Both stated that for their brothers or father, the only expectation was for them to contribute financially.

Nadia stated,

"After I get home from work, I have to help with any household chores that need to be done. It used to really bother me that I was expected to work all day and then come home and help with cleaning and cooking. I don't have a problem with doing any household chores, but I would feel anger and resentment knowing that I work just as hard as say my dad or brother, but at the end of the day, they don't do any of the household chores, and no one says anything. And if I don't do it, I'm told that it is my job to help out and that's what women are supposed to do."

Sana's experience also echoes that of the other participants. However, for Sana, she also

has the additional responsibility of taking care of her nine-year-old son. Sana explained,

"For me, I go to school full-time and work part-time. Any spare moment I have, I try to spend it with my son and do my best to ensure that all his needs are taken care of. I am also expected to cook and clean on certain days for my family. Trying to balance everything has been tough, and my parents do try to help me with taking care of my son when I need it. However, they are getting older, and it's difficult on them too. So, while I do wish I had less responsibility, there isn't much that can be done. I do think my brothers could do more around to help out with the cooking and cleaning; however, they cling to the belief that men don't have to do any work in the kitchen".

These experiences highlight how in some South Asian households, patriarchal gender dynamics are still present in the division of domestic labour even when the women are working outside of the house in paid employment. As well, women such as Shreya are subjected to intensely gendered surveillance that governs her coming and going from her family residence.

\section{$\underline{\text { Identity Crisis }}$}

Shreya, Nadia, and Sana were born and raised outside of Canada. They all moved to Canada before the age of fifteen and completed their primary and secondary education here. All 
three of the participants shared that they have experienced an identity crisis at some point in their lives. An identity crisis is defined as a time where one is filled with uncertainty and, confusion as they question their sense of self or identity (Baumeister, Shapiro, \& Tice, 1985). An identity crisis can be experienced when faced with a personal conflict which leads one to question who they are and their role in society. It can also be experienced when one is questioning things such as your values, spirituality, beliefs, interests, or career path that have a major impact on how you see yourself (Baumeister, Shapiro, \& Tice, 1985).

Shreya explained that for her, the identity crisis stemmed from not knowing where she fits in. Shreya stated,

"I just never felt like I belonged anywhere, and this feeling took me to a place where I felt uncomfortable everywhere. When I would go visit my family in India, I felt out of place. We all spoke the same language but our beliefs, values, thought processes... all of that was different. And here in Canada, it was the same thing. I was too Western for my family in India, and I was a little too Indian for people in Canada."

This led to Shreya feeling socially isolated and questioning exactly where and how she fit in to the society where she lived.

Sana had a similar experience. She shared,

"I don't really know if there is a place I would feel entirely at home or where I would belong. I speak several languages, including English, French, Urdu, and Punjabi. In Montreal, I experienced racism because I used to wear the hijab, so I never quite fit in there. In Toronto, there was a lot more diversity; however, some part of me still felt like an outsider as my English was not as great as my French. When I moved back to Pakistan, it was a very strange experience. I was in the house where I was born and surrounded by all my relatives and the people that helped raise me. And yet that feeling that I did not belong still remained. I come from a very traditional area where the ultimate goal of every young woman is to get married and have children, and that was the last thing that I wanted for myself."

Sana shared that not knowing where she belonged played a role in making her question her identity and who she was. Sana also shared that being forced to accept certain roles such as 
becoming a wife before she was ready or wanted led to a period in her life where she was very depressed:

"I was nineteen years old and married before I wanted to be. I was being told by other people how I should live my life and what was the correct way. I struggled every morning wondering where I do belong, who I am now, and is this what my life is?"

She also shared that while she spoke many languages and was part of all these different worlds, she felt like she didn't belong to any of them, and this led to her identity crisis.

\section{Addictions and Substance Use}

All of the participants in this study shared that they used either nicotine, alcohol, and/or cannabis at some point in their life. Shreya, Nadia, and Sana each specified that there were various reasons for their drug or alcohol use. They specified that there had been instances where they used alcohol and cannabis due to their mental health. They stated that they used substances to cope with the adverse impacts of their mental health that were caused by family issues, school, work, or other stressors. Shreya stated that she had family members that struggled with alcohol addiction. Nadia and Sana both stated that they were the only ones in their family that they know of their substance use as the rest of their family are practicing Muslims. They stated that if any family members used substances or struggled with addiction, they would not know about it because, in their Muslim family and community, drugs and alcohol are strictly forbidden. Therefore, family or community use of any substances or struggle with addictions is dealt with privately and not discussed openly.

Shreya shared that her own father struggled with an addiction to alcohol. She stated,

"My dad struggled with an addiction to alcohol, after years of heavy drinking, he was diagnosed with cirrhosis of the liver and got very sick. He was put on life support more than once and, each time, we were told that he wouldn't recover this time. He did eventually recover and received a liver transplant and is now in recovery. But despite how bad his addiction got, no one ever acknowledged that mental health impacted and 
influenced his addiction. Rather me and my mom were approached by many family members who told us that as his wife and daughter, we could get him to stop drinking if only we talked to him. My mom was always blamed when he would drink and was always told that she should be able to stop him. Also, while men in my community can drink alcohol without a problem, if women are seen drinking it impacts their reputation negatively and they are seen as bad."

Shreya discussed that members of her family and community would place responsibility on her and her mother because, as women, they were expected to be the moral compass of the family and be able to control her father's drinking. Since Shreya and her mom could not stop her father from drinking, they were blamed for his drinking, absolving her father from any accountability for his actions and choices. Shreya's experience is consistent with current literature that states the in some South Asian communities, the burden of a family's honour is unequally placed upon the women of the family, such as the daughters, daughters-in-law, sisters, wives, and mothers (Chew-Graham et al., 2002).

Shreya shared that dealing with her father's addiction lead to the deterioration of her own mental health. In addition to being forced to take responsibility to control her father's drinking at a young age, Shreya explained that she could not share what she was experiencing with anyone else. Because addiction was not something that is discussed in the community and they are taught that these are private matters that should not be talked about outside of the family, Shreya had to deal with the impacts alone. There was no one that she could speak with and share what she was experiencing. Shreya stated that those who knew about her father's struggle with addictions also shamed her when she used cannabis or had her first drink of alcohol. Shreya expressed frustration that it took so long for her to understand that her father's drinking was not normal and that he was not just drinking because it was something that men do. Rather the 
drinking was a symptom of a deeper issue that stemmed from her father's overall adverse mental health and had underlying biological, psychological, and social reasons.

Being shamed and isolated with no one to turn to lead Shreya to experience extreme anxiety. Shreya shared,

"I started having panic attacks. They start off small. I didn't even realize what it was at first, they eventually got longer and occurred suddenly without any warning. At one point, I was about to write an exam at university, and I experienced a panic attack. A T.A. had to help me get into the hall outside of the exam room, and everything went black, I was on the floor rocking back and forth and eventually was I laying down in fetal position. When I eventually felt better enough to have some control over myself and spoke with the T.A, I asked if I could still write the exam. I was told it was too late for me to write it. I thought my panic attack only lasted at most five minutes, but it turned out to be thirty or forty minutes."

Within Muslim South Asian communities, addictions and substance use is often hidden as using any substances is a sin, and to acknowledge that you are using or dependent on a substance is to admit to going against the teaching of the religion. For Muslim women, who already have added pressures to conform to rigid cultural and gender roles, there are additional consequences of being further marginalized and stigmatized if they are found to be using substances or dependent on substances. Shreya's experience shows how within South Asian communities where alcohol and substances are used and not seen as religious taboos, women are discouraged from drinking alcohol as it has social implications on their reputation in the community. In contrast, men do not face the same consequences if they consume alcohol and the responsibility of how much the men consume, and their behavior while intoxicated becomes representative of the women in their family.

Many South Asian cultures hold collectivist values where a person is not only accountable for themselves but also their family, friends, and the wider community. Due to values in which the culture is grounded in, for many South Asian communities, caring for an 
individual with mental health concerns and substance dependency, becomes seen as a family responsibility. Family relationships play an integral role in the lives of all community members, especially the women. In order to protect members who face mental health concerns or substance dependency from stigma and to protect the family's reputation, there is a tendency to not disclose the existence of adverse mental health or substance dependency. As a result, individuals that are experiencing mental health concerns are silenced when sharing their struggles and can be left feeling increasingly isolated.

Within many South Asian communities, the social pressure to conform and adhere to cultural and social norms is important as there is a tendency within such communities to often view anyone outside of these norms as abnormal. Adherence to social norms, especially by women is seen as critical to achieving and maintaining respect and standing within the community. This includes excelling academically, being employed, getting married and having children. To live outside of these norms by having mental health concerns which can impact success in school, employment and relationships can damage reputation and reinforce feelings of shame and produce secrecy. Social pressures also increase the isolation of individuals with mental health concerns as they cannot share what they are going through with others; conversely, other individuals from the community may refrain from speaking with individuals who are living with mental health challenges because they fear being seen as associated with such individuals.

For many first-generation South Asian women in Canada, there is additional pressure to adhere to social norms and conform to cultural norms in order to be seen as successful by their South Asian communities' standards. For some, this pressure also stems from their parents who seek validation that the sacrifices they made in the process of immigrating to Canada were worth it as it ensured a better future for their children. This can create intergenerational and cultural 
conflict for these women who moved to Canada at a young age and want to adopt to the society they grew up in but must also live up to the prevailing standards of many South Asian communities. These women also hold the burden of needing to validate their parents' decision to immigrate to Canada by shining in academia and their careers. This can further negatively impact their mental health by exacerbating stress, the fear of failure, and feelings of being a disappointment. This requires first-generation South Asian women to work towards finding a way to express their individuality within a collectivist community and create autonomy for themselves with limited support from their family.

The findings of my study correspond with the current literature regarding South Asian mental health which found that some of the mental health stressors that were faced by South Asian women and other communities members included intergenerational and cultural conflict, patriarchal gender roles in the household, identity crisis, and addictions and substance use (Ahmad et al., \& Stewart, 2005; Hussain \& Cochrane, 2002; Islam et al., 2017; Samuel, 2009). The pressures of balancing two different cultures, having enforced patriarchal gender roles that were difficult to break away from, questioning their identity, where they belonged, and learning to navigate addictions and substance use all negatively impacted these women's mental health.

\section{Theme 3: Barriers to Mental Health Service Access}

The three participants of this research study, Shreya, Nadia, and Sana, all highlighted the different barriers that they face when accessing mental health services. Of all the barriers identified, four main barriers were mentioned by each of the participants. These barriers include affordability and long wait times, lack of culturally responsive services, and discouragement within the community and culture. The participants of this study have all accessed mental health 
services in the city of Toronto. The participants all noted that they became aware of services that were available by searching the internet.

Shreya, Nadia, and Sana noted that there were many services that they were aware of that were offered in the city of Toronto, ranging from walk-in services to telephone counselling. The first barrier that participants identified in accessing mental health services were affordability and long wait times. The participants all stated that when they were looking to access services, they were informed of long wait times before they could access a professional.

Shreya stated that when she tried to access a counsellor,

"I waited on the phone for close to an hour before I reached a staff member. Once I was able to speak with a staff member, I was informed that the first step would be to complete an intake session with one of the counsellors. After the intake session, I would be matched with another counsellor. It took over four weeks for me to receive a call for the intake, and at that point, I figured I could just figure things on my own and did not see the point in continuing with an intake and waiting several more weeks to get an in-person appointment."

Sana stated that when accessing a therapist, she was only able to go in for a single inperson session. Sana noted that she was unable to continue sessions as she was unable to afford them. She explained,

"After the initial session, I realized that I would still be paying $\$ 80$ - \$120 for a one-hour session. This was with a therapist that offered a sliding fee scale based on income. Between paying for school, all my other expenses, and only working part-time, I simply couldn't afford to pay that much. Considering how important mental health is to wellness, it's a shame that OHIP cannot cover any of the costs... as far as I am aware."

As a single mother who only worked part-time, Sana was unable to afford to continue accessing mental health services.

Lack of culturally responsive services was also mentioned by all three participants as a barrier to accessing mental health services. Shreya stated that she accessed a therapist through her school. She made the decision to receive counselling to help her process the events that were 
occurring in her life that left her with anxiety, panic attacks, and feeling isolated. Shreya stated that she felt that the counsellor could not understand what she was experiencing and, at times, thought that she was being judged. She shared,

"The counsellor focused a lot of academics and spent a good part of the session trying to move the conversation to get me to figure out that I was just stressed and overwhelmed because of school. And while I was to some degree, that wasn't my main concern. I was also dealing with other things like family issues and being alone, but she kept going back to academics. And when I did share about my family, the responses that I would get were basic, like have you tried being open and sharing your feelings with your mom or that my main focus should be on myself and my family members are adults that need to take responsibility for their own actions. Although that's great in theory, things don't work like that in our family. You don't just think about yourself and your own needs, you think about the whole family. The counsellor was white, and so I first had to explain how things work in my family, community and culture; I could just see that she was struggling to understand, and I could feel the judgement."

During a time when Shreya needed a safe and inclusive space where she could be listened to, understood, and provided with resources, she ended up leaving feeling more alone and judged. Shreya shared that she would have continued to access counselling had the counsellor used a person-centred approach and inquired about the intersecting forms of discrimination she experienced and its impacts on her mental health and how it impacted her socially.

In Canada, the education system, including teachers, administration, social workers, and counsellors, is rooted in colonialism. Lee and Ferrer (2014) examine how the residential school system was created to forcibly assimilate Indigenous peoples into the dominant Canadian society as part of the process of the circle of civilization. The education system has been utilized as a colonial tool to establish Canada as a white settler society. This has allowed Eurocentric dominant worldviews to guide practices and teachings in the system, which is problematic as it "others" everyone who does not adhere to this worldview (Lee and Ferrer, 2014). As seen in Shreya's experience, the counsellor emphasized individualism and 
struggled to understand Shreya's social and cultural practices. The counsellor's continuous reinforcement of individualism reflects the colonial project in which European settlers worked to remove collectivist ways of knowing to replace it with European worldviews, which exalt individualism and individual rights. By forcing a Eurocentric worldview, the counsellor left Shreya to feel that her social and cultural practices and knowledge were devalued, leading her to feel isolated, alienated, and inclined to withdraw from further sessions.

Nadia's first point of contact before connecting with additional mental health services was her doctor. Her mother took her to see their family doctor once she discovered that Nadia was using cannabis recreationally. Nadia shared that her mother has a close relationship with their family doctor, and that was the only individual that she felt comfortable sharing any information with. Her mother felt comfortable disclosing Nadia's experience with anxiety or depression with the family doctor. Nadia was given anti-anxiety medication, but she refused to see a mental health professional. Nadia shared that it has been challenging to get someone to understand how her intersecting identities influence her relationships and mental health. Since the medical and mental health professionals could not understand her experience or the culture that she was raised and lived in, she found accessing services not to be effective and left her feeling worse than before.

Nadia shared,

"It's really hard finding a therapist or even a doctor that understands my point of view. I remember when I went to the doctor with my mom when I was an adult to do a drug test. The doctor advised me to make my mom trust me and also told me how I was also part of the problem... I ended up yelling at her saying how she doesn't understand how my culture works. I can't make my mom trust me because even the normal things I do, say like wear a skirt makes her distrust me because it goes against her religion ... or if I come home after the sun sets because in our culture girls have no business being out late. When I found a therapist, I was told that I should look into getting medication instead of 
providing me with a holistic view of being able to take control of your life and behaviours. I think the issue is doctors and mental health professionals tend to provide me with a lot of medications, but most of my problem is not being able to cope within an environment that is stressful and not being able to have the mental capacity to think about normal everyday things without feeling anxiety. Like I don't want medication ever. And it's often pushed down my throat because I often feel overwhelmed."

Nadia's experience correlates to the findings in the literature review, where participants felt that there was an excessive focus on treating mental health through medication without considering how religion and other social factors affect mental health (Islam et al., 2017; Samuel, 2009).

Sana shared that she was able to connect to another therapist through a referral from her family doctor. She stated that she went for a few sessions; however, she did not find them particularly helpful as she could not build rapport with the therapist due to cultural differences. She stated,

"When I went to counselling, I did find it helpful to share what I was going through with someone. It was a relief to share some of the things I have never told another person. However, it was very exhausting having to explain my culture, the environment that I grew up in, and why I have to make some of the decisions that I do. It was difficult to explain why I couldn't just get a divorce because of the stigma in my community or that I agreed to get married in the first place because I did not want to be disowned by my family. And while what they wanted from me was not what I wanted, losing them would be worse for me. I live in a country where I do not have any other relatives or too many close friends, so without my family, I could be completely alone. I found that my therapist was very so solution-focused, which isn't bad; however, for me, it wasn't helpful because the solutions that they were offering weren't right for me."

It was noted that for Sana, she did see the benefit of accessing mental health supports and having a space where she could share her thoughts and feelings. Sana shared that she believes she could have had a better experience had the therapist understood aspects of her culture without her having to explain.

The current dominant paradigm that operates in Canada is a Western paradigm, which is based on Western culture. Western culture refers to the values of European settlers and their descendants, which consists of specific social norms, ethical values, traditional customs, specific 
artifacts and technologies, and a set of "literary, scientific, musical, and philosophical principles" (Stewart, 2007, p. 55). Within the Western tradition, mental health has generally been defined in relation to illness. In Canada, most mental health practitioners' training and practice stem from a Western paradigm. Therefore, dominant cultural attitudes and beliefs based on Western European philosophies and practices inform counselling approaches (Stewart, 2007). These cultural attitudes and beliefs that inform counselling approaches exalts Western worldviews and produce cultures that emphasize individualism, private property, and free well. Western worldview is also a part of the colonial project that aimed to eradicate all other ways of knowing to exalt Eurocentric ways of knowing. Sana's experience illustrated her struggle to find a mental health practitioner whose training and practice did not stem from a Western paradigm and could understand the worldviews that she held and the interlocking systems of oppression she faced as a racialized woman. Her experience also showed that it is crucial to reconstruct dominant paradigms to challenge established dominant narratives that promote the modern exclusion of racialized groups. Reconstructing our knowledge also helps to re-shape and determine who can speak, how they are heard today, and providing legitimacy to voices that have historically been silenced. (Lee and Ferrer, 2014).

The participants noted that another barrier to obtaining services was their culture and community, which discouraged people from accessing mental health services. Shreya, Nadia, and Sana highlighted that they were raised to believe that certain things should not be shared with anyone outside of the family. All three of the participants discussed that there was distrust of mental health services in their community, especially around the lack of confidentiality. As well, the participants stated that their families tended to encourage them to access religious supports rather than mental health services. 
Shreya shared that no one had ever accessed formal mental health services in her immediate and extended family. She explained,

"In my family, no one ever considers getting therapy, and part of the reasons that happens is because mental health is stigmatized. There is a fear of what others will think if they know that you have to go see a therapist. I also find that mental health is confused for mental illness, and so when we do talks about mental health, were actually always discussing mental illnesses. With my own, mom it took me a lot of years to finally get her to understand the concept of mental health, and even now, she only feels comfortable talking to her family doctor about it and would never consider going to an actual therapist. Part of it, I think, is because she is afraid of other people finding out that she saw a therapist, and the other part of it is knowing that there is someone out there that has notes one what you are thinking and going through."

Nadia shared that for her, her family actively encouraged her to seek religious

intervention. She noted the following,

"I was actively encouraged to talk to an Imam or anyone else who they thought had a lot of Islamic knowledge to help guide me. When I shared that I felt anxious all the time or that it would get to the point where I felt chest pains, I was told that the best solution is to pray and that it would help me feel a lot better."

Sana shared a similar experience as follows,

"At first, I thought something was wrong with me that I was not normal because at home we did not speak of mental health. I got to a point where I spent two years just staying at home with my son. I wouldn't go out, I stopped talking to any of my friends, and the only people that I saw were my family. Growing up and even now, if we had any problems like depression, anxiety, it was considered the personal failings of the individual. I was also taught that the answer to all my problems big or small should be praying to god and asking god for helping and that talking to anyone else about what I was going through wouldn't make any difference. If I ever shared with my family that I wanted to access mental health services, they would tense up and say there was no need for those, and the only people that used those were the ones that we're crazy. Because of that, it took a long time for me to even consider using mental health services. I really do believe that if mental health was discussed more and we weren't distrustful of the services that were offered, I would have accessed them a lot soon, before I reached a point of crisis."

The participants' experiences highlighted that there is a prudent mistrust of western

psychiatry, which harms racialized women such as Shreya, Nadia, and Sana, in South Asian

communities. These misunderstandings and misconceptions are also often passed through 
different generations. This creates barriers for individuals struggling with their mental health to accessing the formal supports they need as they are subjected to attitudes that promote stigma, marginalization, discrimination, isolation, secrecy, and shame regarding mental health. For the first generation immigrant women that I interviewed, while they reside in a society that is now starting to work towards addressing mental health, they also live with family members who were born and raised in a non-Western society where ways of knowledge and responses to mental health did not resemble those of Western World views.

For Shreya, Nadia, and Sana, their families can be both caring and isolating. The participants shared that their family relationships play an influential and integral role in their lives. While their families have in some way created obstacles for them when it comes to accessing mental health supports, the women all shared that they believed that their parents were trying to raise them the best they could given their own struggles and the worldviews they were raised with. The women shared that their families cared about their health and wellbeing and wanted to see them succeed academically and in their careers. Their families' lack of awareness and understanding regarding mental health impacted their parents' ability to understand mental health and recognize the symptoms of adverse mental health and not support them in obtaining formal support.

It can be challenging for many South Asian women to talk to their parents regarding their mental health and substance use. Some parents might be more likely to turn solely to faith-based interventions and to problematize the effects of adverse mental health such as poor academic success rather than focusing on the underlying mental health issue (Ahmad et al., \& Stewart, 2005; Islam et al., 2017; Samuel, 2009). While faith-based interventions are essential for some individuals to achieve wellness, they may not be right for some women like Nadia and Sana. It is 
important to note that some parents might be more open than others to learning about their children's understanding of mental health and encouraging them to use their agency to determine for themselves what supports they require to improve their mental health.

\section{Theme 4: Coping strategies}

Throughout the interview process with Shreya, Nadia, and Sana, we discussed many of the struggles that they faced in their daily lives. However, it was evident that despite the obstacles they faced, the participants all demonstrated resiliency. Coping strategies can help one tolerate, minimize, and deal with stressors in their life. Some traditional coping strategies used to address mental health struggles include but are not limited to distracting oneself, mediating, managing hostile feelings, and using systematic relaxation procedures. The three participants in this study shared different coping strategies that they used to help them address their mental health.

All participants shared that they worked towards forming their own community to help provide them with the support that they needed and could not find elsewhere. The participants all stated that they found and/or formed their communities in different ways.

Shreya shared that she was able to form her own little community filled with friends who she knew faced similar challenges. She stated the following,

"I have my own community that I can turn to when I need support. It's made up of people that I went to elementary school with. All of us were girls who came from somewhere in South Asia. We all moved to Canada around the same time, and through talking over the years were all became close and realized that we shared many of the same experiences."

Nadia shared that she was able to find over the Internet different communities of likeminded individuals who had similar experiences. She explained,

"I'm a part of several different support groups, all for different things. I searched for them online and found some that were active on social media sites like Facebook. A lot of 
them also had in-person meetings or group chats that I was able to be a part of. Through this, I was able to meet real people that were going through the same things as me.

Having the internet has made a huge difference in being able to find and connect with people that know what you are going through and have similar experiences."

Sana stated that once she started university, she was able to form a community among the people in her program, "Some of them became very close friends of mine and knew me better than my own family. These are people I can turn to when I need support."

Shreya and Nadia shared that art was something that helped them with their mental health. It was an outlet for their emotion and allowed them to express themselves. Both Shreya and Nadia shared that they paint as a coping strategy. Shreya shared,

"for me, art is therapeutic, and it allows me to express my authentic self. I don't have to hide who I am or please anyone but myself." Nadia stated that her art was liberating, "In my own life, I often felt that I had no control over anything. However, when I paint, I have something that I can take control of and do as I want with no consequences."

Through the use of art, Shreya and Nadia demonstrated how their coping strategy engaged in holistic approaches to healing.

Sana shared that one of her coping strategies to address her mental health was obtaining a part-time job and constantly checking in with herself. She explained,

"This might seem strange, but I think of working, even though it is only a part-time as a coping strategy. Working allows me to be able to have a tiny bit of financial security. It's not much money, but it lets me realize that I don't have to rely on anyone else, I can be independent. It also allows me to have work experience, which will be helpful after I finish school and look for a full-time job. Since I'm also busy and juggle between a lot of responsibilities, I make sure to check in with myself at least once a day to see how I am doing and what I am struggling with that day."

Shreya, Nadia, and Sana all worked towards finding and utilizing coping strategies that helped them combat their adverse mental health. The findings of this study correlated with the 
findings of the literature review which assert that South Asian women utilize alternative coping strategies which help them deal with their mental health despite the barriers and intersecting identities they face such as building their own communities, increased efforts to socialize and the use of self-awareness (Ahmad et al., 2005).

The literature review also highlighted that support within immediate and extended South Asian American families was also seen as a possible coping strategy for some (Masood et al., 2009). This was the case for Shreya and Sana, who mentioned that their support network included their cousins who are around their age and also first-generation immigrants. Coping through seeking social supports reflected the collectivistic roots of South Asian cultures, which are also reflected in the participants' values and beliefs (Masood et al., 2009; Tummala-Narra, et al., 2016).

Below are the art pieces that were shared with me during the interview process by Nadia and Shreya. As the original ethics application submitted and approved by Ryerson University's Research Ethics Board did not include a request to add the participant's artwork in the research paper, a request to reopen the ethics protocol was made. The protocol was reopened to request permission to send a follow-up email to the participants (Appendix F) to obtain consent (Appendix G) to use their drawings in the dissemination. The REB granted approval for this endeavour. 


\section{Nadia's Artwork}

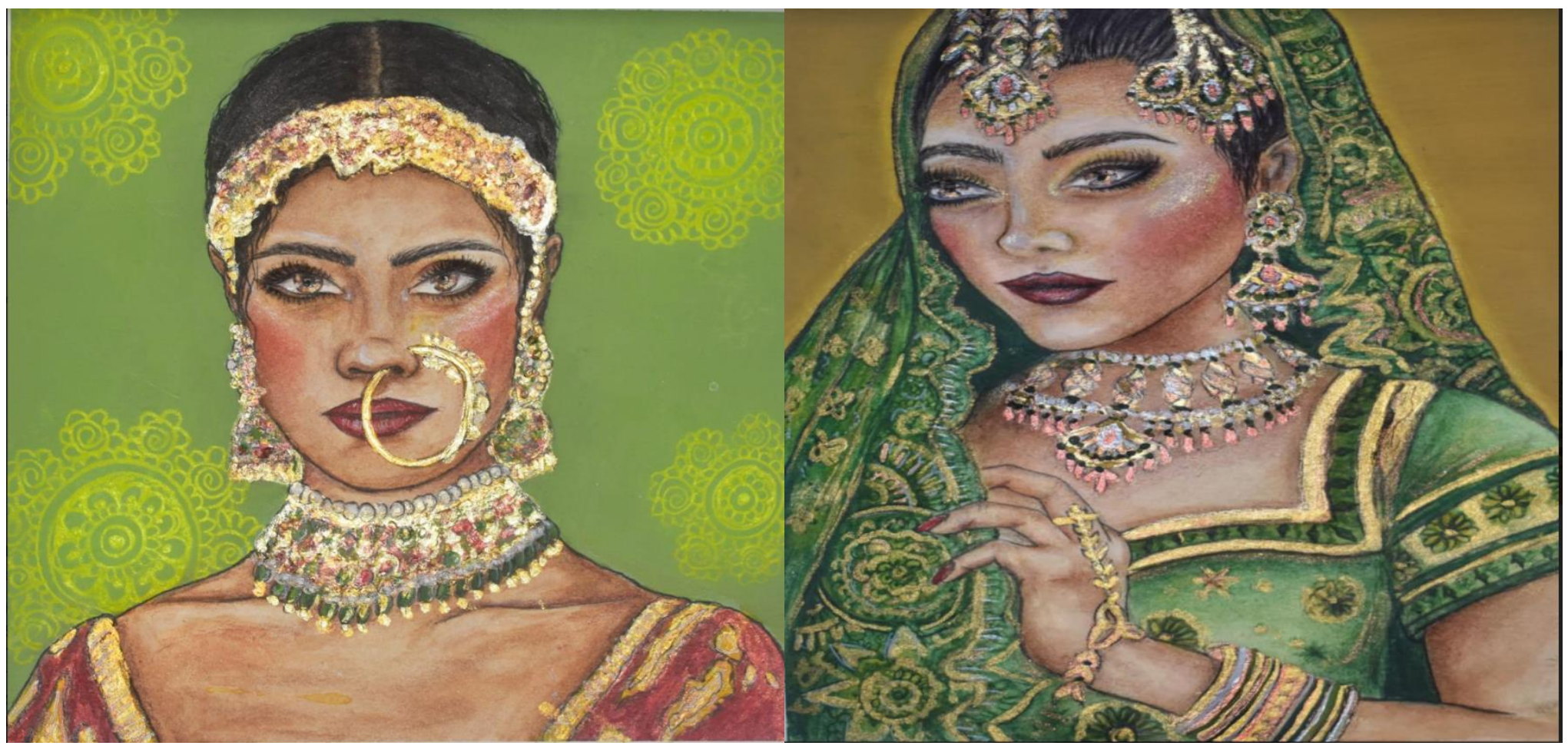

\section{Shreya's Artwork}
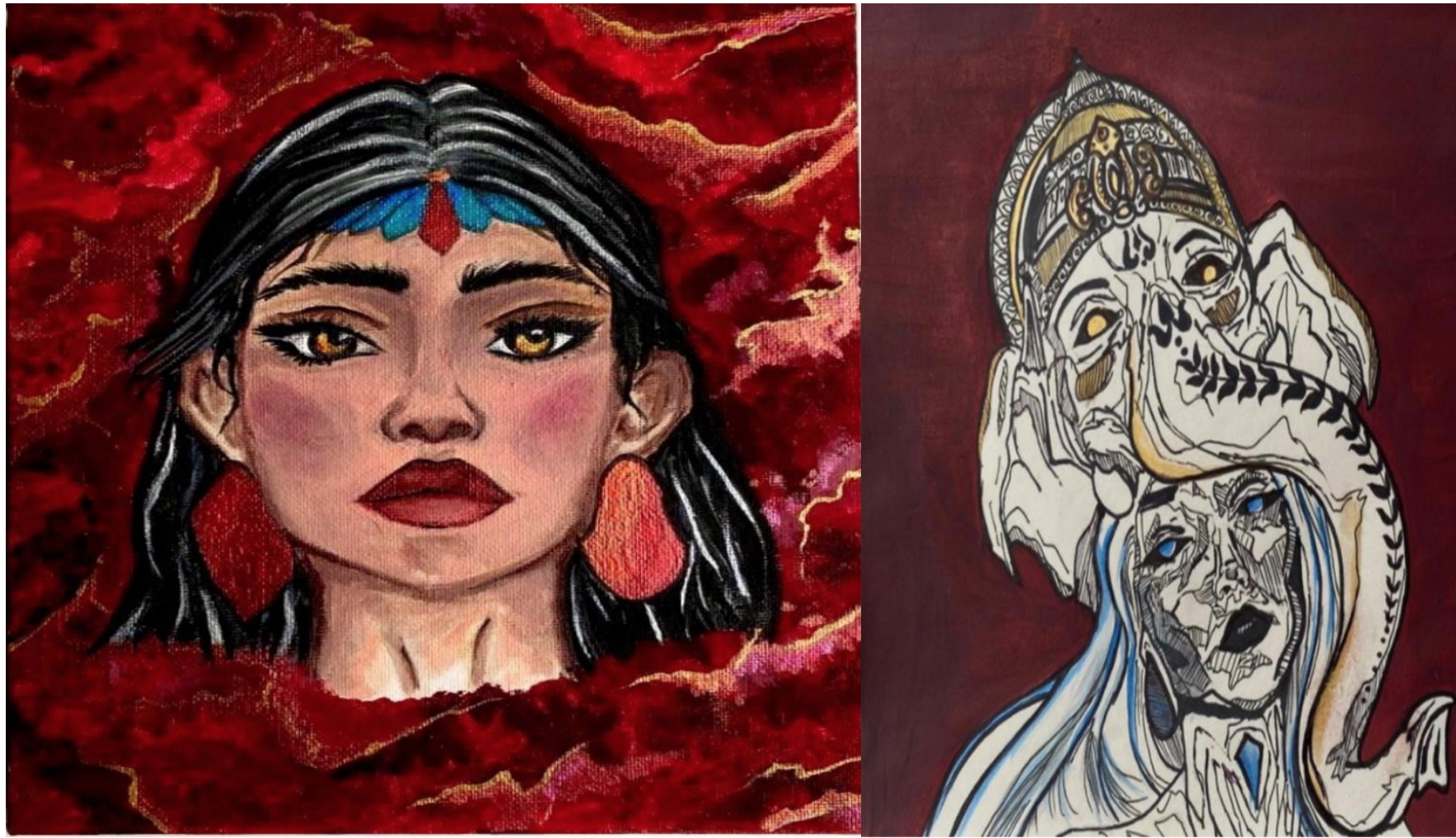


\section{Chapter 6: Implications}

My original research question asked, "What mental health experiences are faced by firstgeneration South Asian women, and what are their experiences of accessing support services in Toronto?" My research findings were only able to capture a fragment of the various ways in which first-generation South Asian women experience mental health and accessing mental health support services. This speaks to why more research is necessary to understand the full scope of how intersecting identities impact mental health and accessing support services. I was very fortunate to find participants who could share the story of their experiences and journey with me and allowed me to present it in this study. As for my research question, I found that there is no singular experience as each journey is unique to each individual; however, there are commonalities. It is important to note that the participants' experience is not representative of all first-generation South Asian women and that social determinants of health, one's social location, values, and beliefs can drastically impact mental health experiences.

What is evident from this study was that there is a vast amount of knowledge available in these women's narratives. These voices that are usually missing or discounted from literature and the dialogue regarding mental health need to be heard. Furthermore, for South Asians, especially women, there is a lot more work that must be done in the community, and on systemic and institutional levels to raise awareness regarding mental health to mitigate the adverse effect of mental health challenges and remove the barriers that prevent access to mental health services.

\section{Recommendations:}

In collaboration with the researcher, participants of the study made key recommendations that they felt were necessary for service providers and the South Asian community. These recommendations were compiled during the interview process to help improve mental health 
among South Asian women and to address the challenges faced by the wider community in accessing mental health services. These recommendations help provide culturally responsive services, solutions, and education that come from service providers and South Asian people themselves.

\section{The following is a list of some of the key recommendations made:}

- More education is required to allow community members to learn the basic signs and symptoms of mental health and addiction concerns. This includes common signs that are often ignored or go unnoticed, such as but not limited to loss of motivation, loss of energy, and changes to sleeping or eating patterns.

- Within the South Asian communities, there is a lot of ethnic, religious, and linguistic diversity. When working with South Asian women, service providers should ask the individual to describe their own community and family to obtain a better understanding of their identity and how they perceive mental health.

- Service providers and schools must work towards normalizing mental health in order to challenge the notion that mental health and discussions of mental health are taboo and something to be ashamed of.

- South Asian communities must encourage dialogue and education regarding mental health in order to actively fight against stigma within the communities and to promote awareness on how mental health affects one's well-being.

- South Asian communities need more leaders who strive for progressive change within the community locally. This can be done by building up the communities with arts, literature, youth hubs, and career networking. This can help combat social isolation and provide them with a safe and inclusive space where they feel comfortable, listened to, and understood. 
- Schools and service providers must understand that within South Asian communities, there is a distrust of systems of authority (teachers, Children's Aid Society, police, social workers). This distrust may keep many South Asian women from discussing their mental health concerns or accessing mental health services. Work must be done to build trust with the community.

- Service providers should assess South Asian women for intersections of gender, sexual orientation, race, class, religion, family history, and encourage dialogue about these experiences and how they contribute to their mental health.

- Service providers must understand that some South Asian women experience rigid cultural and gender roles that are imposed on them. This may impact their mental health or prevent them from seeking support. Breaking away from these roles is a complex process that requires time and can create further struggles in the family and community.

- Service providers should be aware that for some South Asian women, their families may encourage them to seek supports from faith leaders. It is important to respect the family's cultural belief system and understand that this may work for some South Asian women. However, remain cognizant that prayer, religious intervention, and meditation will not work for everyone. Therefore, advise service users and families about different Western mental health supports that are also available to them.

- Service providers should utilize holistic approaches to mental health and recovery and take into account biological, psychological, social, and spiritual factors that impact mental health rather than just treating the symptoms. Be open to incorporating alternative mediums of expression such as including art, music, poetry, storytelling, and journaling to allow South Asian women to articulate their thoughts and feelings. 
- Service providers must understand that it can be difficult for South Asian women to talk to parents and family members about their mental health and substance use, and the subsequent impacts on their life. Therefore, it might not always be possible to incorporate their family into their recovery plan and support network.

- Service providers must understand that intergenerational trauma, multiple migrations, and colonialism are all factors that should be understood and integrated into work with South Asian women.

- South Asian communities must work towards creating and fostering a supportive home environment with open communication and dialogue.

- Service providers should aim to provide person-centered support that allows South Asian women to determine what personal needs, wants, and goals are central to their care.

\section{Limitations and Strengths:}

Akin to all research that is conducted, there are both limitations and strengths in this study. One of the major limitations of this study is the small sample size of three participants. The study's small sample size and qualitative design inhibit the study's findings from being applied to a wider population or generalized to all South Asian communities. Another major limitation of this study is the short timeframe that did not allow for more South Asian women's voices. The timeframe also affected my ability to recruit participants from community organizations as the process to obtain permission requires more time than I had to complete the study. 
Despite the limitations, this study presented the narratives of three South Asian women who had unique lives and yet shared commonalities on how their social location impacted their mental health and their experience of accessing mental health services. The participants were also able to provide data that indicated a need for more research regarding mental health from a perspective of racialized women as race, immigration, culture, and gender all play a significant role in shaping mental health. The research participants also illustrated that it is necessary to incorporate diverse perspectives in research to provide an anti-essentialist standpoint on the experiences of women of color.

The historical utilization of the social work profession as a colonial tool to establish Canada as a white settler society is something that must be critically analyzed as it laid the foundations for many of our current practices. In a country where the racial demographic is rapidly changing with immigration from all over the world, we cannot have practices in the social work profession that are covertly racist. Historically, the social work profession has participated in different social practices of inclusion/exclusion, and these practices continue today (Lee \& Ferrer, 2014). The historical role of having social work be a whitedominated profession is one reason that there are very few racialized perspectives in the writings used by Canadian schools of social work (Lee \& Ferrer, 2014). This allows the dominant Eurocentric worldview to guide social work practice.

\section{Implications for anti-oppressive practice (AOP):}

From an anti-oppressive social work perspective, AOP is committed to addressing inequalities, power dynamics, questioning normative practices, and dismantling structural systems of oppression (Turney, 1997). Therefore, this research has implications for AOP and social workers as the findings show the importance of engaging with marginalized and racialized 
communities in the city of Toronto due to the barriers they face when accessing mental health supports. By engaging with these communities, more accessible pathways to mental health care that provide culturally informed mental health supports and services can be created. AOP is additionally devoted to engaging in decolonizing research (Turney, 1997). Similar to $\mathrm{AOP}$, the process of decolonizing disrupts whiteness in knowledge production and works to support the voices of individuals that are often ignored and marginalized through the favouring of certain knowledges (Sakamoto, 2007). It also ensures that service providers, researchers, and educators question rigid belief systems that do not represent everyone (Sakamoto, 2007). This research also demonstrates that more decolonizing research is needed to present alternative narratives that highlight the strength, diversity, and resilience of women's voices from the Global South.

According to Yee and Wagner (2013), an anti-oppressive framework aims to address systemic oppression and critically analyze systemic inequities. The approach also looks at how there many intersecting sources of inequality. AOP also highlights the importance of understanding the history of different groups that have been marginalized within our society. There are limitations currently on how an anti-oppressive framework can be applied in contemporary social work practice as neoliberalism principles heavily influence it. Neoliberalism has impacted the way we can use an anti-oppressive approach in the social work profession. It has dismantled the social welfare state, cut funding for social services and programs, and social spending. Neoliberalism also pushed for the privatization of public resources and encouraged businesses and corporations to solve social issues (Lee \& Ferrer, 2014). Neoliberalism has allowed a greater emphasis to be placed on individuals. The idea of meritocracy is highly valued, and those who require state intervention are punished (Lee \& Ferrer, 2014). There is still much 
work that has to be done to remove covertly racist and colonial practices. While an antioppressive practice and framework teach us a lot on how to make a difference in the lives of marginalized and oppressed people, there are many systemic barriers that we still must fight to dismantle.

\section{Future Research:}

We must continue to work towards legitimizing the knowledge of racially othered cultural groups, which can allow South Asian communities themselves to work towards addressing the mental health needs of their own people. Minority groups have often been victims of stereotyping, and any alternatives are given little opportunity to exist or be accepted. We must understand and allow the individual to express individual experiences, acknowledging that these will continually change (Hussain \& Cochrane, 2002). Multiple realities and experiences were shared in this study rather than only highlighting one individual's truth. People and realities are complex and cannot always be easily categorized. Therefore, it is important to include narratives that highlight this. I hope that by highlighting the existence of multiple truths, we understand the diversity that is present within the South Asian community.

Social science research often reveals a story that becomes a dominant narrative. Within the dominant story, whiteness and masculinity are assumed to be the norm, and other experiences are outliers. Therefore, non-racialized and masculine voices end up speaking for other groups and telling their stories according to the dominant narrative. The role of storytelling and presenting counternarratives is to actively push back against the dominant narrative that is told repeatedly. More research is needed that is developed by people of colour and includes the voices and stories of racialized people in order to dismantle dominant narratives and highlight 
counternarratives. In order to do so, South Asian people must be included in research and research development to legitimize their voices and narratives.

This research study showed that there are several areas that could be explored further in research. Future research must explore on a larger scale how South Asians experience mental health and the stressors that they face that hinder recovery. Research can also carefully examine how more culturally responsive services would benefit and encourage more South Asian women in accessing mental health services. Additional research that analyzes how systems and institutions (economic, social, political, etc.) impact mental health from a South Asian perspective will also be beneficial. 


\section{Chapter 7: Conclusion}

For the first-generation South Asian women that I interviewed, mental health was seen as a taboo subject within their family and South Asian communities. As a result, within the family and South Asian communities, there was minimal open and honest discussion regarding mental health, mental health stressors, mental health services, and coping strategies. In this study, the women that I spoke to all shared how their intersecting identities, such as gender, race, and religion, played a role in shaping their overall identity and impacted their mental health. In this MRP, I gained a better understanding of some of the systemic and daily challenges that these women faced and how it impacted their mental health. I also learned that despite the struggles that they faced, these women demonstrated incredible resiliency. Through their resourcefulness, work ethic, and motivation, these women were able to discover what coping strategies worked best for them.

The participants expressed hope that they will see changes in the way that mental health is seen and discussed. They also wanted to see their communities rise to the challenge of addressing mental health's adverse impacts and seeing it as a vital part of wellness. The participants offered several key recommendations for how service providers, schools, and South Asian communities can help improve South Asian women's mental health.

As stated in the implication section, one of this study's major limitations is the short timeframe that did not allow for the voices of more South Asian women. During the process of transcribing the interviews, I also realized that the research would have benefitted from a second interview that could go more in-depth around certain topics with the participants. A second interview could have allowed me to ask participants how their coping strategies have impacted their mental health and daily lives. It would have also allowed me to ask if the participants had 
noticed any changes in their mental health through the years since they arrived in Canada. It would also allow us to understand if the women foresaw any changes in the gender dynamics of their households. A second interview was not possible as the ethics application only allowed for one interview, and the participants only committed to one interview.

As immigrant women and South Asian immigrant voices are rarely heard in literature, more research on the topic will be beneficial for the field. Large scale and longitudinal research that allows for more time and support participants in sharing their experience can provide meaningful insight into how to remove barriers to accessing mental health support and change attitudes and behaviours that lead to adverse mental health for South Asian women.

Despite the limitations, this study can contribute to the field by filling a minor gap in the limited literature and the dialogues regarding South Asian mental health by including these voices that are usually missing or discounted. My research participants and I hope this study can be used as a small stepping-stone to pave the way for further research with this population and around the topics explored in this MRP. We all strongly felt that as others have done before us, we too have an obligation to ourselves and the generations after us to share our stories, to strive for more, and to carve a space in the world for us that will be better for us all. 


\section{APPENDIX A - Recruitment Email}

\section{Study Title:}

Within These Walls: Examining the Mental Health Experiences of First Generation South Asian Women in Toronto, Canada

Hello,

My name is Aneesa Atta. I am currently a student at Ryerson University, and I am conducting research as part of my study in the Master of Social Work Program. My research aims at exploring the mental health experiences of immigrant women.

I would like to explore the mental health experiences of first-generation South Asian women in Toronto, Canada. The research aims to examine how the intersecting identities (race, sexuality, gender identity and expression, religion, and spirituality) of South Asian women impact their mental health. In addition, I would like to look at the possible barriers that they might experience in accessing mental health services in the city. Furthermore, I would like the research to critically explore some of the strengths, limitations, barriers, and gaps in the current mental health services offered in the city for the South Asian community. I hope that this research will show the importance of engaging with marginalized and racialized communities in the city to create more accessible pathways to mental health care that provide culturally informed mental health supports and services.

This study requires participants to engage in a 1 to 1.5 hours audio record interview. Due to COVID-19, the interviews will take place by phone or through an online video call. This study is voluntary; the participant can choose to skip questions or withdraw from the study at any time. Confidentiality would be assured throughout the research process.

The Ryerson Research Ethics Board has reviewed and approved this study (REB 2020-073). I look forward to hearing from you. For more information, please contact me at aneesa.atta@ryerson.ca.

Thank you.

Yours sincerely,

Aneesa Atta

MSW Candidate

School of Social Work

Ryerson University

Email: aneesa.atta@ryerson.ca 


\section{APPENDIX B- Recruitment Flyer}

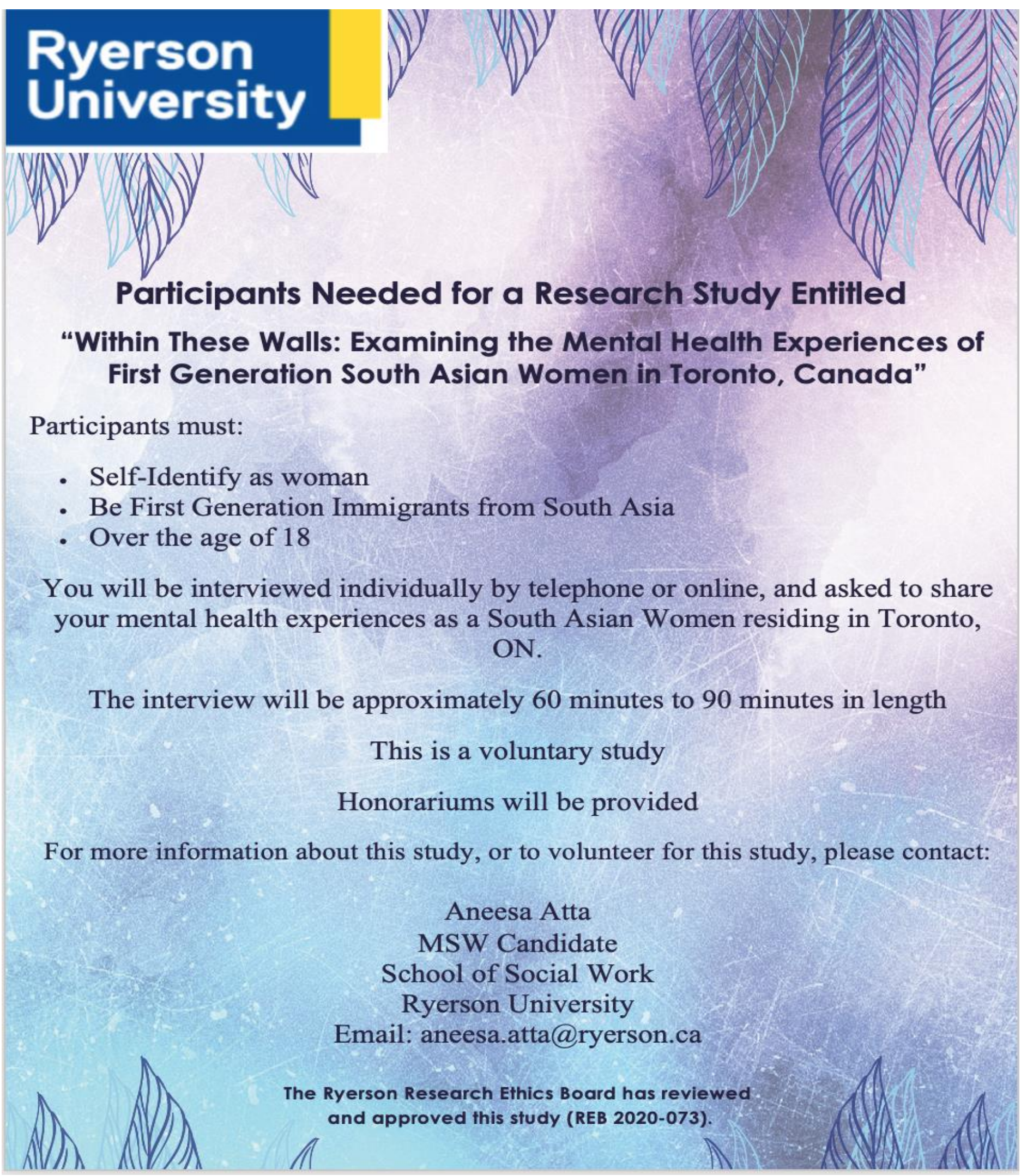




\title{
APPENDIX C- Consent Form
}

\author{
SCHOOL OF SOCIAL WORK \\ FACULTY OF COMMUNITY SERVICES
}

\section{Ryerson University \\ Consent Agreement}

You are being invited to participate in a research study. Please read this consent form so that you understand what your participation will involve. Before you consent to participate, please ask any questions to be sure you understand what your participation will involve.

\section{Within These Walls: Examining the Mental Health Experiences of First Generation South Asian Women in Toronto, Canada}

\section{INTRODUCTION AND PURPOSE:}

My name is Aneesa Atta, and I am currently completing my Master of Social Work degree at Ryerson University. As a part of my degree, I must complete an individual research study. My research, entitled Within These Walls will explore the mental health experiences of firstgeneration South Asian women in Toronto, Canada. I am seeking a total of three participants for this study. The aim of the research is to closely examine how the intersecting identities (race, sexuality, gender identity and expression, religion, and spirituality) of South Asian women impact their mental health and the possible barriers that they might experience in accessing mental health services in the city. Furthermore, I would like the research to critically explore some of the strengths, limitations, barriers, and gaps in the current mental health services offered in the city for the South Asian community. I hope that this research will show the importance of engaging with marginalized and racialized communities in the city to create more accessible pathways to mental health care that provide culturally informed mental health supports and services.

As a graduate student, I will be supervised by Dr. Gordon Pon, who has conducted several years of research in the field of anti-racism, anti-Black racism, and anti-colonialism within Ontario.

\section{WHAT YOU WILL BE ASKED TO DO:}

Within the study, you will be asked to share your experiences regarding your mental health experiences as a first-generation South Asian woman in Toronto. I also wish to co-construct this knowledge with you and have discussions on themes you would specifically want to highlight within this research. This will happen through a one-on-one interview with me (through phone or a video call), which may take up to 1.5 hours.

I want to ensure you are aware that this is a voluntary study, and at any time in this process, you are free to withdraw. 


\section{POTENTIAL BENEFITS:}

I cannot guarantee that you will receive any benefits from participating in this study. However, the research will contribute to filling the gap in understanding the mental health experiences of first-generation immigrant women.

\section{WHAT ARE THE POTENTIAL RISKS TO YOU AS A PARTICIPANT?}

There will be a low risk in this research. Some of the low risk includes: You have to take time off your normal duties to participate in this study and the time frame of the study will be challenging. The length of time is challenging because the study will take about 1-1.5 hours of your time. You might experience some discomfort discussing certain aspects of your mental health experiences.

\section{CONFIDENTIALITY:}

Your identity will be kept confidential throughout the research. I will use pseudonyms (fake names) to identify participants. The student researcher (myself) and supervisor will be the only ones with access to the data. Data will be deleted from audio device after the submission of the final research paper. Any laptop and/or USB used for the study will be password protected. The transcribed data will be stored on a password protected laptop. Our data of the recorded interviews will be retained by me until August 2020, after which they will be destroyed. All data will be stored on the Ryerson Google Shared Drive, as it is secure and encrypted, minimizes the risk of data being accessed by unauthorized individuals, and facilitates the sharing of data without need for transportation or duplication of data. The information gathered will never be released to any other party for any reason, without your full consent.

The only way confidentiality may be breeched by me is if you disclose any child abuse, which will compel my duty to report to Children's Aid Society. In addition, if you disclose that you are a current risk to yourself, or others, then I will also be required to complete duties to report.

\section{INCENTIVES FOR PARTICIPATION:}

A $\$ 20.00$ honorarium will be provided to you in the form of a visa gift card.

\section{VOLUNTARY PARTICIPATION AND WITHDRAWAL:}

This study is completely voluntary, and you may withdraw from this study for any reason. Due to the time constraints of this study, you will have until Saturday, May 30th, 2020, to withdraw your interview. After your withdrawal, your information will be disposed of within 48 hours. Withdrawal from this study will not influence future relations with Ryerson University, affiliates, or the primary researcher Aneesa Atta and Dr. Gordon Pon.

If any question makes you uncomfortable, you can skip that question. Please note you may stop participating at any time, and you will still be given the incentives described above. 
DATA DISSEMINATION: This research is being completed by Aneesa Atta, a graduate student in the School of Social Work. The results will contribute to her major research paper in partial completion of her Master's degree.

QUESTIONS ABOUT THE STUDY: If you have any questions about the research now, please ask. If you have questions later about the research, you may contact me via phone or email.

Primary Investigator:

Aneesa Atta

Master of Social Work Student

aneesa.atta@ryerson.ca

Supervisor:

Dr. Gordon Pon

Associate Professor

Ph.D., M.S. W

g2pon@ryerson.ca

416-979-5000, ext. 4786

This study has been reviewed by the Ryerson University Research Ethics Board (REB 2020073). If you have questions regarding your rights as a participant in this study, please contact:

Research Ethics Board

c/o Office of the Vice President, Research and Innovation

Ryerson University

350 Victoria Street Toronto, ON M5B 2K3

416-979-5042

rebchair@ryerson.ca 


\section{Ryerson University}

\section{Within These Walls: Examining the Mental Health Experiences of First Generation South Asian Women in Toronto, Canada}

\section{CONFIRMATION OF AGREEMENT:}

I agree to participate in the study and have been informed that I can change my mind and withdraw my consent to participate.

Due to the time constraints of the research, the deadline to withdraw Saturday, May 30th, 2020. I have been informed that by signing this agreement, I am not giving up any of my legal rights.

I have been given a copy of this agreement.

Name of Participant (please print)

Signature of Participant

Date

I agree to be audio/video-recorded for the purposes of this study. I understand how these recordings will be stored and destroyed. 


\section{APPENDIX D - List of Resources}

\section{South Asian Women's Centre}

Address: 800 Lansdowne Ave Unit 1 Toronto Downtown West Toronto ON M6H 4K3 Canada Website: http://www.sawc.org/

Phone: 416-537-2276

Email: info@sawc.org

\section{Women's Health in Women's Hands Community Health Centre}

Website: http://www.whiwh.com/

Address: 2 Carlton St Suite 500 Toronto Downtown Central Toronto ON M5B 1J3 Canada Phone: 416-593-7655

Email:info@whiwh.com

\section{Council of Agencies Serving South Asians}

Website: http://www.cassa.on.ca/

Address: 5200 Finch Ave E Unit 301A Scarborough North Toronto ON M1S 4Z5 Canada Phone: 416-932-1359

Email: cassa@cassa.on.ca

Naseeha Youth Helpline: +1 866-627-3342

Mental Health Crisis Line: available 24/7, call: 1-866-996-0991

Crisis Service Canada: 1-833-456-4566; or text \#45645 (English only) from 4 p.m. to 12 a.m.

Big White Wall: online 24/7 support

Good 2 Talk: 1-866-925-5454 


\section{APPENDIX E - Interview Guide}

Participating in this study is voluntary. If any question makes you uncomfortable, you can skip it at any time or end the interview. If you choose to stop participating, you may also choose not to have your data included in the study. However, it will be explained to them that after May 30, 2020, they will not be able to remove their data from the study because it will already have been integrated into the overall analyses. Confidentiality will be kept throughout the interview and research process. Please do not provide any identifying information of clients such as names or addresses.

The interview today will be audio recorded to support the analysis of the data. Audio files will be stored on a password protected, encrypted USB, and deleted once the data has been coded and analyzed. Names and other identifying information will not be part of the analysis. You will only be identified by a unique participant code assigned to you. Demographic information such as your age, gender, immigration status, ethnicity, will be collected.

1. Can you tell me a little bit about yourself?

2. Why did you decide to participate in this study?

3. Please share what a typical day in your life is like? (What duties does it consist of?)

4. Demographic information:
a.) Age
b) Number of years residing in Canada
c) Education level

5. Can you tell me a little bit about your family/immigration process?

6. What does "mental health" and "recovery" mean to you?

7. How would you describe your own mental health?

8. Do you feel you can openly discuss your mental health with the people in your life?

9. Have you faced any significant mental health challenges? If you, what are they?

10. Who/what were your key supports?

11. What are some barriers that you, as a South Asian woman have experienced when trying to access mental health services?

12. Do you have any recommendations on how mental health services can be improved to meet your needs? 
13. Are there any intersecting aspects of your identity (such as race, sexuality, gender identity and expression, religion, and spirituality) impacted your experience of mental health?

14. Is there anything that you do to take care of your mental health?

15. Is there anything else that we have not yet covered, and you would like to talk about? 


\section{APPENDIX F - Follow Up Email}

\section{Study Title:}

Within These Walls: Examining the Mental Health Experiences of First Generation South Asian

Women in Toronto, Canada

Hello,

I am currently following up with you to obtain your consent to include your artwork in the dissemination of research paper that I am completing as a part of my study in the Master of Social Work Program.

By signing the consent form below, you will be granting me with non-exclusive rights to use the art images that you provided during the interview phase of this study in the final paper that will be presented to Ryerson University.

The Ryerson Research Ethics Board has reviewed and approved this request (REB 2020-073). I look forward to hearing from you. For more information, please contact me at aneesa.atta@ryerson.ca.

Thank you.

Yours sincerely,

Aneesa Atta

Master of Social Work Student

School of Social Work

Ryerson University

Email: aneesa.atta@ryerson.ca 


\section{APPENDIX G - Artwork Consent Form}

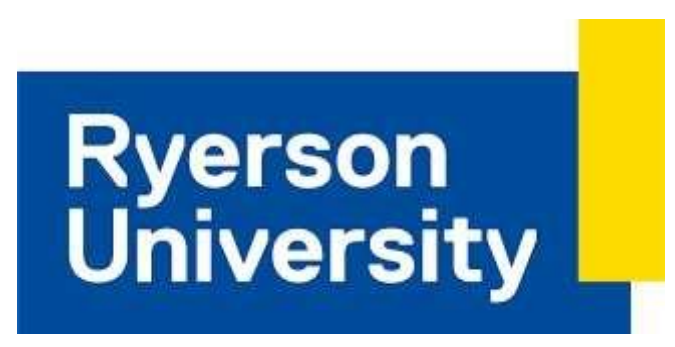

\section{Within These Walls: Examining the Mental Health Experiences of First Generation South Asian Women in Toronto, Canada}

\section{CONFIRMATION OF AGREEMENT:}

I agree to have my artwork presented in the study and have been informed that I can change my mind and withdraw my consent.

Due to the time constraints of the research, the deadline to withdraw my consent is Saturday, August 22, 2020. I have been informed that by signing this agreement, I am not giving up any of my legal rights to my artwork.

I have been given a copy of this agreement.

Name of Participant (please print)

Signature of Participant

Date

I agree to have my artwork presented in this study. I understand how these images will be stored and destroyed. 


\section{REFERENCE LIST}

Absolon (2011). The roots: Paradigms, worldviews and principles. In Kaandossiwin: How we come to know (pp. 53-66). Halifax \& Winnipeg: Fernwood Publishing.

Absolon, K. \& Willett, C. (2005). Putting ourselves forward: Location in Aboriginal research. In L. Brown \& S. Strega (Eds.), Research as Resistance pp. 97-126. Toronto: Canadian Scholars’ Press.

Ahmad, F., Shik, A., Vanza, R., Cheung, A. M., George, U., \& Stewart, D. E. (2005;2004;). Voices of South Asian women: Immigration and mental health. Women \& Health, 40(4), 113-130. doi:10.1300/J013v40n04_07

Arat-Koç, S. (2010). New whiteness (es), beyond the colour line? Assessing the contradictions and complexities of 'whiteness' in the (geo) political economy of capitalist globalism. In S. Razack., S. Thobani, \& M. Smith (Eds.), States of race: Critical race feminism for the $21^{\text {st }}$ century (pp. 147-168). Between the Lines.

Arora, P. G., Metz, K., \& Carlson, C. I. (2016). Attitudes toward professional psychological help seeking in South Asian students: Role of stigma and gender. Journal of Multicultural Counseling and Development, 44(4), 263-284.

Baksh (2016). Clarity and confusion: Epistemological struggles with Islamic identity and secular education. Qualitative Social Work, 15(5-6), 640-649.

Baskin C. (2009) Evolution and revolution: Healing approaches with Aboriginal adults. In R. Sinclair, M. A. Hart, \& G. Bruyere (Eds.), Wicihitowin: Aboriginal social work in Canada. Halifax: Fernwood. 
Baumeister, R. F., Shapiro, J. P., \& Tice, D. M. (1985). Two kinds of identity crisis. Journal of personality, 53(3), 407-424.

Bonnie, N., \& Pon, G. (2015). Critical well being in child welfare: A journey towards creating a new social contract for black communities. Walking this path together: Anti-racist and anti-oppressive child welfare practice, 105-123.

Creswell, J., \& Poth, C. (2017). Qualitative inquiry and research design: Choosing among five approaches (4th ed.). Los Angeles, CA: SAGE Publications Inc.

Chamberlain, K., Stevens, C \& Lyons, A. (1997). Encompassing experience: Meanings and methods in health psychology, Psychology and Health, 12, 691-709

Chew-Graham, C., Bashir, C., Chantler, K., Burman, E., \& Batsleer, J. (2002). South Asian women, psychological distress and self-harm: Lessons for primary care trusts. Health \& Social Care in the Community, 10(5), 339-347. doi:10.1046/j.1365-2524.2002.00382.x

Delgado, R., \& Stefancic, J. (2012). Chapter 1. In Critical race theory: An introduction (pp. 116). New York: New York University Press. doi:9780814785294

Dua, E. (1999). Introduction: Canadian anti-racist feminist thought: Scratching the surface of racism. In: Dua E., \& A. Robertson (eds.), Scratching the surface: Canadian anti-racist feminist thought. Toronto, ON, Canada: Women's Press; 7-31.

Said, E. (1978). Introduction to orientalism. Media Studies: A Reader, 111-23.

Few, A. L. (2007). Integrating black consciousness and critical race feminism into family studies research. Journal of Family Issues, 28(4), 452-473.

Fook, J. (2012). Chapter 7: Critical deconstruction and reconstruction, in Social work: Critical theory and practice. London: Sage. 
Fraser, H. (2004). Doing narrative research: Analyzing personal stories line by line. Qualitative Social Work, 3(2), 179-201.

George, U., \& Ramkissoon, S. (1998). Race, gender, and class: Interlocking oppressions in the lives of South Asian women in Canada. Affilia, 13(1), 102-119. doi:10.1177/088610999801300106

Glesne, C. (2016). Becoming qualitative researchers: An introduction. Pearson. One Lake Street, Upper Saddle River, New Jersey

Hunter (2002). Rethinking epistemology, methodology, and racism: or, is White sociology really dead? Race \& Society, 119-138.

Hussain, F. A., \& Cochrane, R. (2002). Depression in South Asian women: Asian women's beliefs on causes and cures. Mental Health, Religion \& Culture, 5(3), 285-311. doi:10.1080/13674670210130036

Inman, A. G. (2006). South Asian women: Identities and conflicts. Cultural Diversity and Ethnic Minority Psychology, 12(2), 306-319. doi:10.1037/1099-9809.12.2.306

Islam, F., Multani, A., Hynie, M., Shakya, Y., \& McKenzie, K. (2017). Mental health of South Asian youth in Peel region, Toronto, Canada: A qualitative study of determinants, coping strategies and service access. BMJ Open, 7(11), e018265. doi:10.1136/bmjopen-2017018265

Kleinman, A. (1987). Anthropology and psychiatry: The role of culture in cross-cultural research in illness, British Journal of Psychiatry, 151, 447-454.

Lavallée, L. (2009). Practical application of an Indigenous research framework and two qualitative Indigenous research methods: Sharing circles and Anishnaabe symbol-based reflection. International Journal of Qualitative Methods. 8(1), 21-40. 
Lee, E. O. J., \& Ferrer, I. (2014). Examining social work as a Canadian settler colonial project. Journal of Critical Anti-Oppressive Social Inquiry, 1(1).

Lynn, M., \& Parker, L. (2006). Critical race studies in education: Examining a decade of research on US schools. The Urban Review, 38(4), 257-290.

Masood, N., Okazaki, S., \& Takeuchi, D. T. (2009). Gender, family, and community correlates of mental health in south Asian Americans. Cultural Diversity and Ethnic Minority Psychology, 15(3), 265-274. doi:10.1037/a0014301

Neuman, W. L. (2013). The meanings of methodology. In Social research methods: Quantitative and quantitative approaches (7th ed., pp. 91-124). Boston: Pearson Education Inc.

Pon, G., Giwa, S. \& Razack, N. (2016). Foundations of anti-racist/anti-oppressive social work practice. In Al-Krenin and Graham, J. (Eds.) Diversity and social work in Canada. Don Mills, ON: Oxford University Press

Potts \& Brown (2015), Becoming an anti-oppressive researcher. In S. Strega \& L. Brown (Eds.), Research as resistance: Revisiting critical, Indigenous and anti-oppressive approaches (2nd ed.) (pp. 17- 42). Toronto: Canadian Scholars’ Press.

Pratt-Clarke, M. (2010). Critical race, feminism, and education: A social justice model. New York: Springer.

Razack, S., Thobani, S., \& Smith, M. (Eds.). (2010). States of race: Critical race feminism for the 21st century. Between the Lines.

Riessman, C. Kohler (2008). Narrative methods for the human science. Thousand Oaks: SAGE Publications.

Sakamoto, I. (2007). An anti-oppressive approach to cultural competence. Canadian Social Work Review, 24, 105-114. 
Samuel, E. (2009). Acculturative stress: South Asian immigrant women's experiences in Canada's Atlantic provinces. Journal of Immigrant \& Refugee Studies, 7(1), 16-34. doi:10.1080/15562940802687207

Statistics Canada. (2013). Immigration and ethnocultural diversity in Canada, National Household Survey, 2011. Catalogue no. 99-010-X2011001

Stewart, S. (2007). Indigenous helping and healing in counselor training. Centre for Native Policy and Research Monitor, 2(1), 53-65.

Surood, S., \& Lai, D. W. L. (2010). Impact of culture on use of western health services by older South Asian Canadians. Canadian Journal of Public Health / Revue Canadienne De Sante'e Publique, 101(2), 176-180. doi:10.1007/BF03404367

Tran, K., Kaddatz, J., \& Allard, P. (2005). South Asians in Canada: unity through diversity. Canadian Social Trends, 78, 20-25.

Tummala-Narra, P., Deshpande, A., \& Kaur, J. (2016). South Asian adolescents' experiences of acculturative stress and coping. The American Journal of Orthopsychiatry, 86(2), 194211. doi:10.1037/ort0000147

Turney, D. (1997). Hearing voices, talking difference: A dialogic approach to anti-oppressive practice. Journal of Social Work Practice, 11(2), 115-125.

Williams, M. (2001). Introduction: The very idea of a theory of knowledge. In Problems of knowledge: A critical introduction to epistemology (pp. 1-12). Oxford University Press.

Yee, J., \& Wagner, A. (2013). Is anti-oppression teaching in Canadian social work classrooms a form of neo-liberalism? Social Work Education: The International Journal, 32(3), 1-18 